\title{
Effect of Blend Composition on Characteristics and Performance of Jatropha Bio-epoxy/Epoxy Matrix in Composites with Carbon Fiber Reinforcement
}

\author{
Mohd Hafiezal Mohd Radzi, ${ }^{\text {aee,* }}$ Khalina Abdan, ${ }^{\text {acc,* }}$ Zurina Zainal Abidin,, \\ Mohd Azaman Md Deros, ${ }^{\mathrm{d}}$ and Mohd Hanafee Zin $^{\mathrm{f}}$ \\ Characteristics and performances of a blended jatropha bio-epoxy/epoxy \\ as a matrix in carbon fiber reinforcement was studied. The amount of bio- \\ epoxy was arranged from $0 \mathrm{wt} \%, 25 \mathrm{wt} \%, 30 \mathrm{wt} \%, 40 \mathrm{wt} \%$, and $50 \mathrm{wt} \%$ of \\ the total matrix. Several analyses were performed to characterize and \\ observe their performance. Fourier transform infrared spectroscopy, \\ thermal analysis, physical characteristics, flammability, and soil burial \\ were conducted, as well as mechanical tests. The results showed that \\ introducing bio-epoxy in the matrix changed characteristics and increased \\ or decreased their performance. Blending more than $25 \mathrm{wt} \%$ of bio-epoxy \\ led to improved thermal stability between $280^{\circ} \mathrm{C}$ to $350{ }^{\circ} \mathrm{C}$ and better \\ biodegradability. However, tensile and flexural strength as well as modulus \\ of elasticity decreased once the proportion of bio-epoxy was greater than \\ $25 \mathrm{wt} \%$. The paper proposed an optimal amount of jatropha bio-epoxy so \\ that an alternative biocomposite application could be introduced to \\ minimize carbon footprint in the environment.
}

Keywords: Bio-epoxy; Jatropha oil, Biocomposite; Fiber carbon; Thermal properties; Mechanical properties

Contact information: a: Department of Biological and Agricultural Engineering, Faculty of Engineering, Universiti Putra Malaysia, 43400 Serdang, Selangor Malaysia; b: Department of Chemical Engineering, Faculty of Engineering, Universiti Putra Malaysia, 43400 Serdang, Selangor Malaysia; c: Laboratory of Biocomposite Technology, Institute of Tropical Forestry and Forest Product (INTROP), Universiti Putra Malaysia, 43400 Serdang, Selangor Malaysia; d: School of Manufacturing Engineering, Universiti Malaysia Perlis, 02600 Arau, Perlis Malaysia; e: Faculty of Engineering Technology, Universiti Malaysia Perlis, 02600 Padang Besar, Perlis Malaysia; f: Aerospace Malaysian Innovation Centre (AMIC), No. 3-601, GMI, 43000 Kajang, Selangor Malaysia;

*Corresponding authors: khalina@upm.edu.my; hafiezalradzi@gmail.com

\section{INTRODUCTION}

Usage of polymer is vast, and all applications currently utilize plastics as one of its main materials. Such plastics are usually made of non-renewable resources, such as petroleum-based polymer. The biodegradation rate of such plastic is long, which causes harm to the environment, especially humans and wildlife in the ocean after the materials are disposed of. A life cycle assessment made to compare synthetic epoxy and bio-based epoxy has revealed favourable results of the bio-based version in terms of environment impact and energy use (La Rosa et al. 2014).

Several studies have been conducted by researchers in the past using renewable resources for composite application, such as sugar palm starch (Jumaidin et al. 2017), hemp oil (Manthey et al. 2012), tannins from trees (Lagel et al. 2016), soybean oil (Takahashi et al. 2008; Roudsari et al. 2014; Wang 2014), polylactic acid (Yusoff et al. 2016; Morales et al. 2017), karanja oil (Kadam et al. 2015), etc. All of these studies have the same 
purpose, which is to introduce and replace existing non-renewable polymer with bio-based polymer and apply it in composite application.

These renewable polymers are inexpensive, have a low processing cost, are easily available, and are abundant compared to a petroleum-based polymer. However, they have some drawbacks, mainly performance-wise, overall due to their biodegradability characteristics. Thus, its application is specific and limited to some areas, such as interior parts of a dry area, or in conditions in which they make use of their main advantage. Otherwise, the biopolymer needs to be modified with fillers or blended with other polymers or biopolymers so that its total characteristics will be enhanced.

Jatropha seed pricing ranges from 0.1 to $0.34 \$ / \mathrm{kg}$ with yield up to 6.5 tons per year (Kalam et al. 2012). System of generating jatropha oil is straightforward, and technology involved in the oil production is readily available (Yee et al. 2011). The overall jatropha oil manufacturing process are: Sowing $\Rightarrow$ Cultivation $\Rightarrow$ Harvest $\Rightarrow$ Seed Dehulling and Cleaning $\Rightarrow$ Oil Extraction $\Rightarrow$ Oil Filtration and Purification $\Rightarrow$ Oil Refining. There are several advantages of the plant that make it a useful plant with a number of potential applications, as suggested by Ariza-Montobbio and Lele (2010). Unlike soybeans, canola and many other agricultural sources of biodiesel, jatropha can be cultivated on marginal and non-agricultural land. This implies that growing jatropha will not result in forgoing food crop cultivation. In addition, it starts producing seeds as early as 12 months after being planted, but the effective yield is obtained only after 2 to 3 years. The jatropha plant remains useful for 35 to 50 years, and its seeds can produce around $35 \%$ oil content. Based on per acre production, jatropha's yield is the second highest, next to that of palm oil. It is quite simple to produce biodiesel from the jatropha, while its waste (deoiled jatropha seed extract) can be used to produce organic fertilizer because it has high contents of protein, nitrogen compounds, and some anti-pest compounds. After 4 or 5 years of treatment with this cake, the soil of this original non-agricultural land will become suitable for planting food crops or trees for reforestation.

A number of studies about jatropha oil have been conducted, such as in bio-diesel improvement (Silitonga et al. 2014; Dharma et al. 2016), coating applications (Gogoi et al. 2015), tribology aspects (Satheesh Kumar et al. 2010), adhesive applications (Aung et al. 2014), etc. A study about jatropha based alkyd was performed on a composite application. It was blended with epoxy resin with expanded graphite as a filler to boost its total performances. Via mechanical tensile test, it was found that blended matrix of jatropha based alkyd resin led to improved distribution and interfacial adhesion between matrix and filler to provide reinforcement, therefore offering an improvement in tensile strength (Gogoi et al. 2014). Aung et al. (2014) had synthesized jatropha-based polyurethane adhesive for wood application and compared with palm oil-based adhesive which possessed poor performance due to multiple saturated acids. Jatropha oil-based adhesive was fond to have better shear strength and better reaction to water, acid, and alkali compared to palm oil adhesive (Aung et al. 2014).

Sammaiah et al. (2014) synthesized jatropha bio-epoxy for the purpose of lubrication application. Jatropha bio-epoxy and soybean bio-epoxy were compared, and both showed comparable characteristics in a high temperature environment (Sammaiah et al. 2014). In a study carried out by Gogoi et al. (2015), jatropha oil was converted into biobased alkyd resin. It was blended with different wt $\%$ of an aqueous citric acid solution for the purpose of improving the performances of the bio-based resin. It was observed that the properties such as curing time, chemical resistance, scratch hardness, thermal stability, and tensile strength of the alkyd resins improved significantly on blending. With $50 \mathrm{wt} \%$ 
jatropha bio-epoxy content, the thermal stability and tensile strength of the blends were improved by $42{ }^{\circ} \mathrm{C}$ and $3.18 \mathrm{MPa}$, respectively. The results suggest a strong influence of the amount of jatropha bio-epoxy and citric acid on the alkyd resins output. The thermal and mechanical properties of the cured films can be further improved by undergoing a postcuring process at $160{ }^{\circ} \mathrm{C}$, and the study indicated suitability of these blends in surface coating applications (Gogoi et al. 2015).

Despite many explorations and investigations on jatropha oil that have been done, usage of epoxidized jatropha oil in composite applications is scarce. In this article, jatropha oil was epoxidized and blended with synthetic epoxy. Then, it was used as matrix in laminated fiber carbon composites. Early studies have been conducted, and they showed promising results for further experimental works (Hafiezal et al. 2017, 2018, 2019). Thus, the aim of this article was to reveal the characteristics and performance trends of blended epoxidized jatropha oil with synthetic epoxy in certain ranges of blended ratios and its limitations when used as a matrix in laminated composite.

\section{EXPERIMENTAL}

\section{Materials}

Sample preparation

Fabrics of woven carbon fiber and glass fiber type S, both of 200 gsm with 2000 tex, were used as the reinforcements. Plain weave type was chosen because it is versatile and possesses the most balanced characteristics amongst other weave types. Synthetic epoxy brand Epoxamite 100 with a slow hardener named 103 was used as matrix in the composite panel (Mechasolve Engineering Sdn. Bhd. Company, Selangor, Malaysia). Composite panel was fabricated using a vacuum infusion process, which used the strategic resin transfer moulding method in an environment condition of $25 \pm 1{ }^{\circ} \mathrm{C}$ and $50 \pm 5 \%$ humidity. After that, it was left to cure for $24 \mathrm{~h}$ prior to use. Jatropha bio-epoxy was fabricated by an in-house laboratory of University Putra Malaysia - Aerospace Malaysia Innovation Center (UPM-AMIC) collaboration, and jatropha oil was supplied by Bionas Sdn. Bhd. Company (Kuala Lumpur, Malaysia). Ten layers of fiber carbon fabric with dimensions of $300 \mathrm{~mm} \times 300 \mathrm{~mm}$ were stacked and wetted by bio-epoxy/epoxy according to experimental design. Samples were cut according to each testing specification described by the testing standards such as ASTM, ISO, and manufacturers.

\section{Experimental sample composition design.}

In Table 1, total experimental design of various composition between carbon, glass fiber and different wt\% of blended bio-epoxy/epoxy were shown. For carbon fiber laminated composites

\section{Methods}

Fourier transform infrared spectroscopy - attenuation total reflection (FTIR-ATR)

The FTIR spectroscopy with ATR technique was used to detect functional groups in both the fully synthetic and the blended jatropha bio-epoxy in uncured and cured forms. The spectra of the material were obtained using an IR spectrometer (Pelkin Elmer Frontier GladiATR; Pike Technology, Madison, WI, USA) that scanned over the sample surface in the range of $400 \mathrm{~cm}^{-1}$ to $4000 \mathrm{~cm}^{-1}$. 
Table 1. Composition Design of Laminated Composites with Various Fibers and wt\% of Blended Bio-epoxy/epoxy

\begin{tabular}{|c|c|c|}
\hline Reinforcement & wt\% of Bio-epoxy & wt\% of epoxy \\
\hline \multirow{4}{*}{ Pure Matrix } & 0 & 100 \\
\cline { 2 - 3 } & 18 & 82 \\
\cline { 2 - 3 } & 25 & 75 \\
\cline { 2 - 3 } & 30 & 70 \\
\cline { 2 - 3 } & 40 & 60 \\
\hline \multirow{4}{*}{ Carbon Fiber } & 50 & 50 \\
\cline { 2 - 3 } & 0 & 100 \\
\cline { 2 - 3 } & 18 & 82 \\
\cline { 2 - 3 } & 25 & 75 \\
\cline { 2 - 3 } & 30 & 70 \\
\hline \multirow{3}{*}{ Glass Fiber } & 40 & 60 \\
\cline { 2 - 3 } & 50 & 50 \\
\cline { 2 - 3 } & 0 & 100 \\
\hline
\end{tabular}

\section{Tensile and flexural test}

A universal testing machine (Model AG-X 250kN; Shimadzu, Kyoto, Japan) was used for testing tensile and flexural properties. Five specimens of $250 \mathrm{~mm} \times 25 \mathrm{~mm}$ were cut from the composite panel according to ASTM D3039/D3039M (2017) for the tensile test. Meanwhile, specimens for flexural test were prepared by taking into consideration the span-to-depth ratio of 40:1 as the minimum according to ASTM D790-17 (2017). This was to ensure the elimination of shear effects during the test. The loading speed for tensile test and flexural test were $4 \mathrm{~mm} / \mathrm{min}$ and $2 \mathrm{~mm} / \mathrm{min}$, respectively. The room conditions for the testing were set at a temperature of $23 \pm 1{ }^{\circ} \mathrm{C}$ and relative humidity of $50 \pm 5 \%$.

\section{Impact test}

Charpy impact tests were conducted according to ASTM D6110-18 (2018) at a temperature of $23 \pm 1{ }^{\circ} \mathrm{C}$ and relative humidity of $50 \pm 5 \%$. The samples were cut into dimensions of $50 \mathrm{~mm}(\mathrm{~L}) \times 13 \mathrm{~mm}(\mathrm{~W}) \times 3 \mathrm{~mm}(\mathrm{~T})$ with a notch in the middle. The tests were performed on three replications by using a mechanical pendulum impact tester, model QC639C (Plasmost Enterprise Sdn. Bhd., Penang, Malaysia). The impact strength was calculated based on the impact energy and cross-section area of the specimen.

\section{Morphology observation}

The morphology of samples was observed under an optical microscope and a scanning electron microscope (SEM) (Hitachi S-3400N; Hitachi, Tokyo, Japan) with an acceleration voltage of $10 \mathrm{kV}$.

\section{Thermogravimetric analysis (TGA)}

Thermogravimetric analysis was conducted according to ASTM E1131-08 (2014) by using a TGA Q500 (TA Instruments, New Castle, DE, USA) instrument to characterize thermal degradation. The two samples weighed $8.35 \mathrm{mg}$ and $6.38 \mathrm{mg}$ for the fully synthetic composite structure and the blended jatropha bio-epoxy composite structure, respectively. 
They were heated from $30{ }^{\circ} \mathrm{C}$ to $600{ }^{\circ} \mathrm{C}$ with a constant heating rate of $10{ }^{\circ} \mathrm{C} / \mathrm{min}$ in a nitrogen flow of $50 \mathrm{~mL} / \mathrm{min}$. The heat resistant index $T_{\mathrm{s}}$ was calculated according to Eq. 1 , where $T_{\mathrm{d} 5}$ is the temperature degradation at $5 \%$ and $T_{\mathrm{d} 30}$ is the temperature degradation at $30 \%$ :

$$
T_{\mathrm{S}}=0.49\left(T_{\mathrm{d} 5}+0.6\left(T_{\mathrm{d} 30} / T_{\mathrm{d} 5}\right)\right)
$$

\section{Differential scanning calorimetry (DSC)}

Differential scanning calorimetry was conducted according to ASTM D3418-15 (2015) using a DSC Q20 device (TA Instruments, New Castle, DE, USA) to determine the thermal transition characteristics. The two samples weighed $6.06 \mathrm{mg}$ and $5.23 \mathrm{mg}$ for the fully synthetic composite structure and the blended bio-epoxy composite structure, respectively. They were heated from $30{ }^{\circ} \mathrm{C}$ to $300{ }^{\circ} \mathrm{C}$ with a constant heating rate of 10 ${ }^{\circ} \mathrm{C} / \mathrm{min}$ in a nitrogen flow of $40 \mathrm{~mL} / \mathrm{min}$.

\section{Dynamic mechanical analysis (DMA)}

Dynamic mechanical analysis was conducted according to ASTM D4065-12 (2012) using a DMA Q800 (TA Instruments, New Castle, DE, USA). Samples of $35 \mathrm{~mm}$ $\times 12 \mathrm{~mm}$ for each composite structure were put in single cantilever mode from $30{ }^{\circ} \mathrm{C}$ to $140{ }^{\circ} \mathrm{C}$ with a constant heating rate of $5^{\circ} \mathrm{C} / \mathrm{min}$ in a nitrogen atmosphere at a frequency of $1 \mathrm{~Hz}$ and an amplitude of $15 \mu \mathrm{m}$.

\section{Fiber volume fraction and density}

Three specimens of $25 \mathrm{~mm} \times 25 \mathrm{~mm}$ were cut from composite panel according to ASTM D3171-15 (2015). The mass of crucible and specimen were measured at $0.001 \mathrm{~g}$ precision, and specimen density was measured by a water displacement density calculator device (Densimeter MDS300; Qualitest, Plantation, FL, USA). Each sample in a crucible was burnt in an electrical muffle furnace at $550{ }^{\circ} \mathrm{C}$ for $2 \mathrm{~h}$. Afterwards, the remaining mass of sample was measured, and volume fraction of fiber was calculated using Eq. 2,

$$
V_{\mathrm{f}}=100\left(M_{\mathrm{f}} / M_{\mathrm{i}}\right)\left(\rho_{\mathrm{c}} / \rho_{\mathrm{f}}\right)
$$

where $M_{\mathrm{i}}$ is initial mass $(\mathrm{g})$ of specimen, $M_{\mathrm{f}}$ is final mass $(\mathrm{g})$ of specimen after combustion, $\rho_{\mathrm{c}}$ is density $\left(\mathrm{g} / \mathrm{cm}^{3}\right)$ of specimen, and $\rho_{\mathrm{f}}$ is density $\left(\mathrm{g} / \mathrm{cm}^{3}\right)$ of specimen in the fiber reinforcement.

\section{Moisture content}

Five samples $(10 \mathrm{~mm} \times 10 \mathrm{~mm} \times 3 \mathrm{~mm})$ were prepared for moisture content $(\mathrm{MC})$ investigation. All samples were heated in an oven for $24 \mathrm{~h}$ at $60{ }^{\circ} \mathrm{C}$. The weight of samples before $\left(M_{\mathrm{i}}\right)$ and after $\left(M_{\mathrm{f}}\right)$ heating was measured to calculate moisture content. Moisture content was determined using Eq. 3,

$$
M_{c}=100\left(\left(M_{i}-M_{f}\right) / M_{i}\right)
$$

where $M_{\mathrm{c}}(\%)$ is the moisture of composite, $M_{\mathrm{i}}$ is initial moisture $(\mathrm{g})$, and $M_{\mathrm{f}}(\mathrm{g})$ is final moisture.

\section{Flammability UL94 horizontal burning}

Three samples with dimensions of $250 \mathrm{~mm} \times 15 \mathrm{~mm} \times 2 \mathrm{~mm}$ were used to test flammability performance according to the horizontal burning UL94 standard test. The 
samples were mounted horizontally with a stand and burned with a torch at around 1200 ${ }^{\circ} \mathrm{C}$ at a $45^{\circ}$ angle of inclination. A flame was ignited at the end of the specimen. This was maintained for $30 \mathrm{~s}$ and then left to propagate until the flame reached the first mark. If the flame reached the first mark in less than $30 \mathrm{~s}$, the sample was considered to have failed the test. Two marks were set on the specimens: the first mark was for the time to start recording, and the second mark was where the flame should stop $(75 \mathrm{~mm}$ from the first mark). The time was recorded until either the flame self-extinguished or the flame reached the second mark. The specimens were left under pre-treatment for $48 \mathrm{~h}$ at $23{ }^{\circ} \mathrm{C}$ and $50 \%$ humidity. If any drops fell due to burning, this was taken into consideration. The burning rate was calculated using Eq. 4:

Burning rate $(\mathrm{mm} / \mathrm{s})=($ Length burned $(\mathrm{mm})) /($ Burning duration $(\mathrm{s}))$

\section{Soil burial test}

A biodegradability test (soil burial) was conducted. The laminated biocomposite and hybrid laminated biocomposite samples were weighed and buried in an individual container of soil in which soil nutrients were added. These tests were conducted at ambient temperature $\left(27{ }^{\circ} \mathrm{C}\right.$ to $\left.34{ }^{\circ} \mathrm{C}\right)$ in an open-air area. The biodegradation was monitored for $120 \mathrm{~d}$ at intervals of $30 \mathrm{~d}$. Each sample would be taken out of the container, cleaned, and then its wet mass was weighed. Then, the sample was washed and dried at $40{ }^{\circ} \mathrm{C}$ for $24 \mathrm{~h}$, so that its dry mass could be recorded. The sample was observed under an optical microscope (Olympus Stream; OLYMPUS Corporation, Tokyo, Japan) to see if there were traces of microorganism activities.

\section{RESULTS AND DISCUSSION}

\section{Curing Behaviour}

As this bio-epoxy was new, it needed to be characterized because the blended elements would provide different properties originating from jatropha bio-epoxy. Figure 1 shows the FTIR-ATR comparison data for both fully synthetic and blended jatropha bioepoxy in uncured and cured forms. These spectra were obtained to identify the difference of functional groups in chemical bonding when jatropha bio-epoxy was added into the matrix.

The spectra could be separated into four regions: $4000 \mathrm{~cm}^{-1}$ to $2500 \mathrm{~cm}^{-1}$, which is for $\mathrm{N}-\mathrm{H}, \mathrm{C}-\mathrm{H}$, and $\mathrm{O}-\mathrm{H}$ single bonds; $2500 \mathrm{~cm}^{-1}$ to $2000 \mathrm{~cm}^{-1}$, which is for triple bonds; $2000 \mathrm{~cm}^{-1}$ to $1500 \mathrm{~cm}^{-1}$, which is for $\mathrm{C}=\mathrm{O}, \mathrm{C}=\mathrm{N}$, and $\mathrm{C}=\mathrm{C}$ double bonds; and $1500 \mathrm{~cm}^{-1}$ to $400 \mathrm{~cm}^{-1}$, which are the fingerprints of the compound that are $\mathrm{C}-\mathrm{O}$ single bonds and $\mathrm{C}=\mathrm{C}$ alkene double bonds.

In the first region, a strong and broad peak at $3452 \mathrm{~cm}^{-1}$ was $-\mathrm{OH}$ stretching, which was higher for uncured fully synthetic epoxy compared to bio-epoxy. This is normally an alcohol with intermolecular bonding. For cured matrices, both bio-epoxy and fully synthetic epoxy were almost at the same intensity. At $2923 \mathrm{~cm}^{-1}$ and $2853 \mathrm{~cm}^{-1}$, the peaks of both bands were medium and sharper, and percentage of transmittance was higher in uncured blended jatropha bio-epoxy compared to fully synthetic epoxy. These were the aliphatic $\mathrm{sp}^{3} \mathrm{C}-\mathrm{H}$ stretching groups of the alkane compound class, and they are commonly found in triglyceride oil (Ishak and Salimon 2013). 
There were no spectrum changes in the second region, which was for the triple bonding spectrum. Meanwhile, in the third region, a broad and sharp peak at $1736 \mathrm{~cm}^{-1}$ was identified only when jatropha bio-epoxy was added. This was the $\mathrm{C}=\mathrm{O}$ stretching of ester groups, which are commonly present in fatty acids (Ezzah 2016).

Then, in the fourth region, where the fingerprints of the materials were, the spectra became less sharp and a little broader in some bands for uncured blended bio-epoxy and fully synthetic epoxy. Both showed the same patterns of peaks but at different intensities. At $829 \mathrm{~cm}^{-1}, \mathrm{C}-\mathrm{O}-\mathrm{C}$ stretching of oxirane group was identified in the blended bio-epoxy as reported in several studies that used bio-based epoxy as well (Manthey et al. 2012; Gogoi et al. 2015; Kadam et al. 2015). There were $\mathrm{O}-\mathrm{H}$ bending of phenol group and carbonyl $\mathrm{C}-\mathrm{O}$ stretching of aromatic ester at $1361 \mathrm{~cm}^{-1}$ and $1295 \mathrm{~cm}^{-1}$, respectively.

For cured blended jatropha bio-epoxy, the spectra were almost identical with those of the cured synthetic epoxy. This was important, as the cross-linking process occurred successfully as the band at $829 \mathrm{~cm}^{-1}$ disappeared in both cured matrices, same as reported by several prior studies (Vlček and Petrović 2006; Chauhan and Chibber 2013; Hazmi et al. 2013; Mincheva et al. 2013). At the end, the fingerprints were different, as most of double bonds were opened out, and the molecules became cross-linked in threedimensional networks. Crosslinking is a bond that links one polymer to another different polymer chain. Those disappeared bonds were where the crosslinks happened for covalent bonds, ionic bonds, etc., for the purpose of strengthening physical properties of the resin.

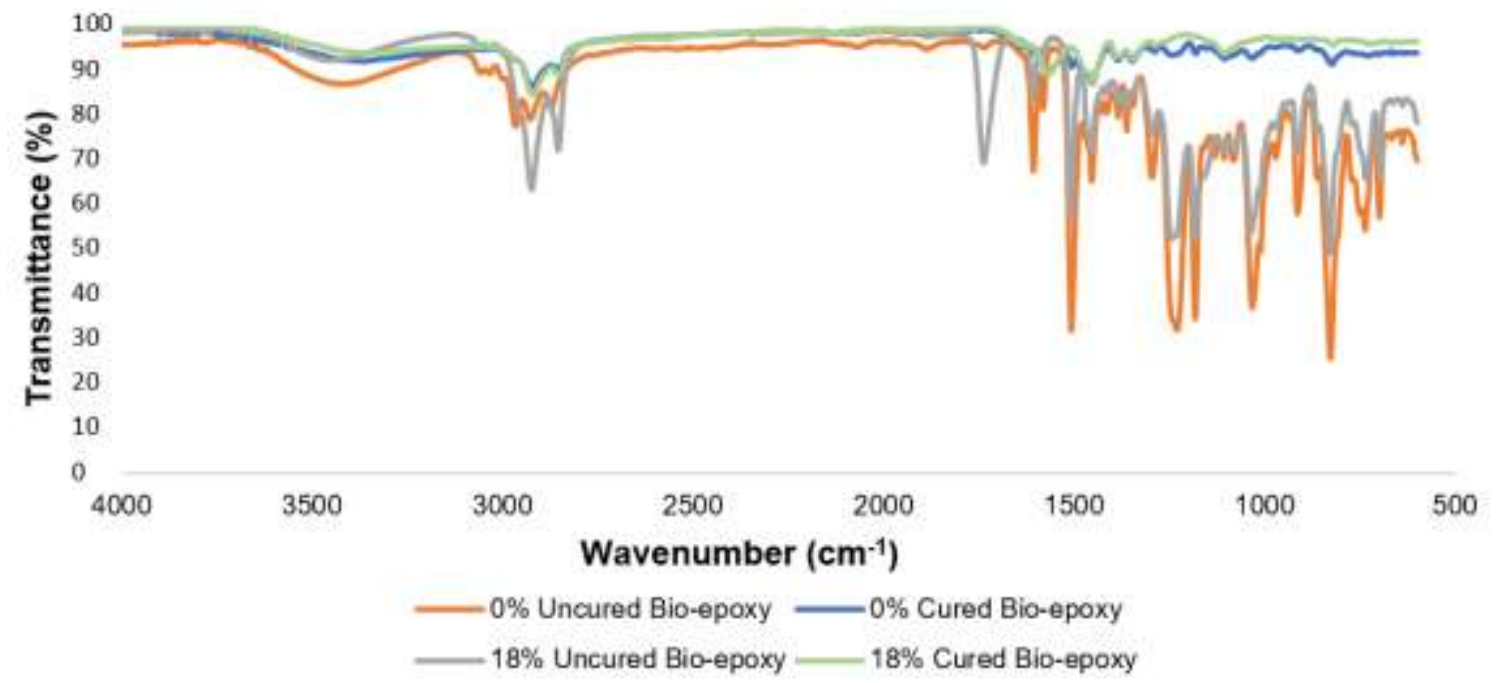

Fig. 1. FTIR-ATR spectra comparison of uncured bio-epoxy and cured bio-epoxy

Figure 2 shows the IR spectra of cured bio-epoxy with incremental variation from $0 \mathrm{wt} \%$ to $50 \mathrm{wt} \%$. At $1500 \mathrm{~cm}^{-1}$ and below, the fingerprint region, the similarity of the peaks between all curvatures was shown, but there was reduced intensity as the bio-epoxy amount increased. At $829 \mathrm{~cm}^{-1}$ the absorbance was attributed to epoxy groups in which the epoxy group became more intense as the wt\% of bio-epoxy increased. This indicated that the amount of bio-epoxy should not exceed a certain ratio to avoid leftovers of epoxy group that were not crosslinked after curing. Up until $25 \mathrm{wt} \%$ bio-epoxy, the peak of epoxy group could be said to be almost non-existent.

From $1508 \mathrm{~cm}^{-1}$ until $1608 \mathrm{~cm}^{-1}$, aromatic stretching was identified, and it became higher when bio-epoxy wt $\%$ increased. From $1600 \mathrm{~cm}^{-1}$ until $1700 \mathrm{~cm}^{-1}$ was the $\mathrm{C}=\mathrm{O}$ bond 
stretching of the ester, and the intensity became higher as bio-epoxy wt\% increased compared to $0 \mathrm{wt} \%$.

At $2855 \mathrm{~cm}^{-1}$ and $2923 \mathrm{~cm}^{-1}$, the $\mathrm{C}-\mathrm{H}$ aliphatic carbon peak was identified. This indicated that the bio-epoxy had a long hydrocarbon chain in the backbone similar to epoxidized soybean oil (Subbiah 2016). Lastly, at $3452 \mathrm{~cm}^{-1}$, O-H stretching was identified, and it became higher as bio-epoxy wt $\%$ increased.

In general, $0 \mathrm{wt} \%$ bio-epoxy was the fully synthetic epoxy that exhibited almost complete crosslinking, with fewer $\mathrm{C}=\mathrm{O}$ bonds, $\mathrm{C}-\mathrm{H}$ bonds, and $\mathrm{O}-\mathrm{H}$ bonding. Meanwhile, as bio-epoxy was blended up to $50 \mathrm{wt} \%$, there was a noticeable presence of $\mathrm{C}=\mathrm{O}, \mathrm{C}-\mathrm{H}$, and $\mathrm{O}-\mathrm{H}$ bonding. For $0 \mathrm{wt} \%$ bio-epoxy, most of the molecules were fully saturated, and not many double bonds were left, as can be seen from the IR spectra. As the amount of bioepoxy increased, more unsaturated molecules were left even after curing process with the same hardener. Fortunately, as the amount of bio-epoxy increased, more aromatic groups could be detected. This led to better thermal stability of the compounds compared to fully synthetic epoxy.

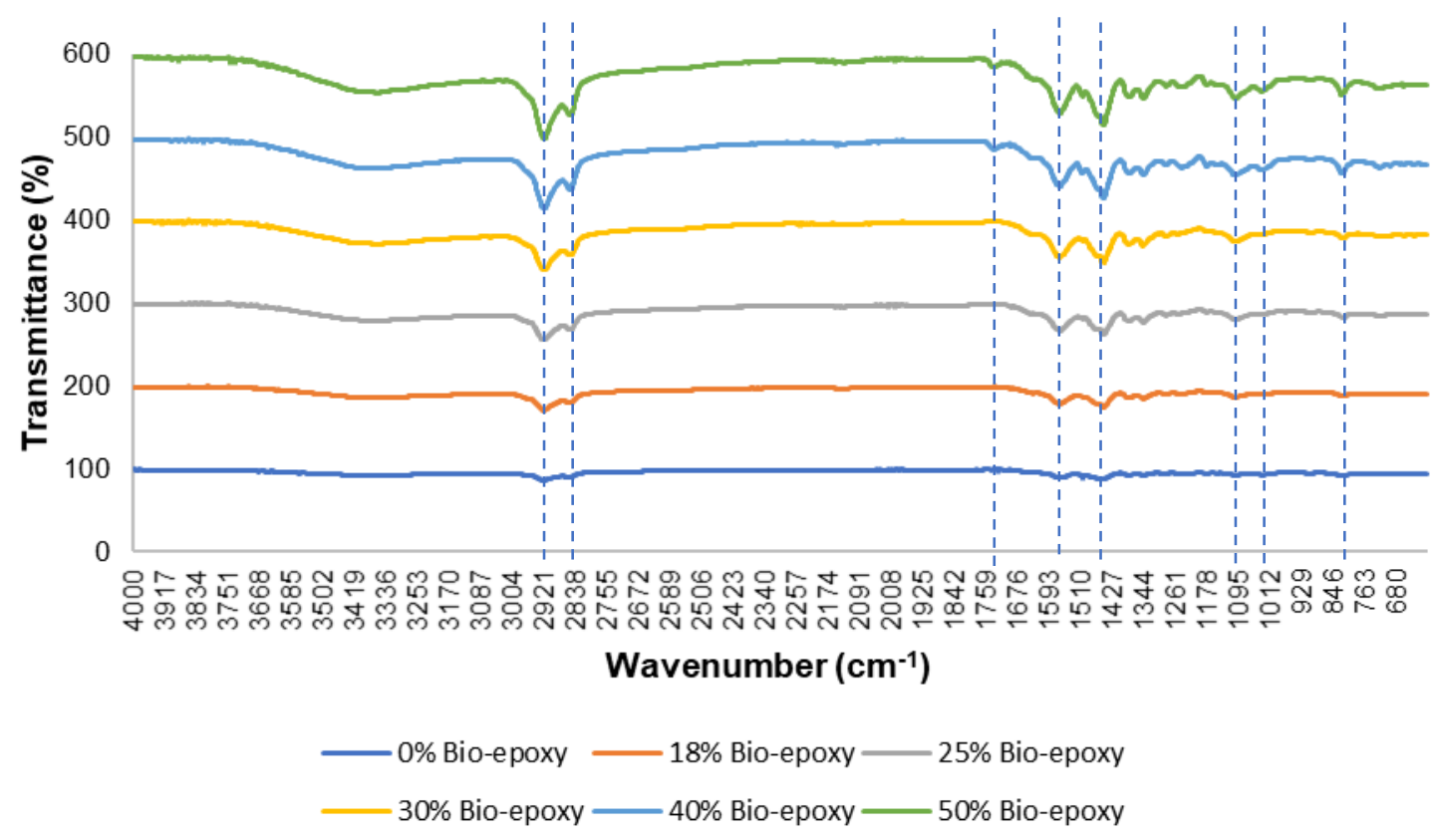

Fig. 2. FTIR-ATR spectra with variation of wt\% of cured bio-epoxy

Chemical reaction of the bio-epoxy can be understood from Fig. 3. Hardener used in this experiment was methylenebiscyclohexanamine,4,4' as shown in Fig. 3(a). It contains two active sites of multiple amine functional groups. Figure 3(b) shows the synthetic epoxy (oxirane, 2,2'-((1-methylethylidene)bis(4,1-phenyleneoxymethylene))bis, homopolymer), while Fig. 3(c) shows the jatropha bio-epoxy (triglyceride) compound, which consisted of at least two epoxide functional group, respectively. All these compounds were mixed for the curing process as presented in Fig. 3(d), where the reactive hardener would crosslink with epoxy and bio-epoxy at the epoxy ring. Note that as anticipated, the amine attacks the least substituted carbon of the epoxy ring which was not protonated. After proton transfer, the product of this reaction has a new N-C bond and an alcohol O-H functional group, resulting a three-dimensioning crosslinking network that 
promoted a very hard thermoset that could be reversed. In addition, the -OH groups help it to adhere to other structures such as reinforced fibers via hydrogen-bonding.
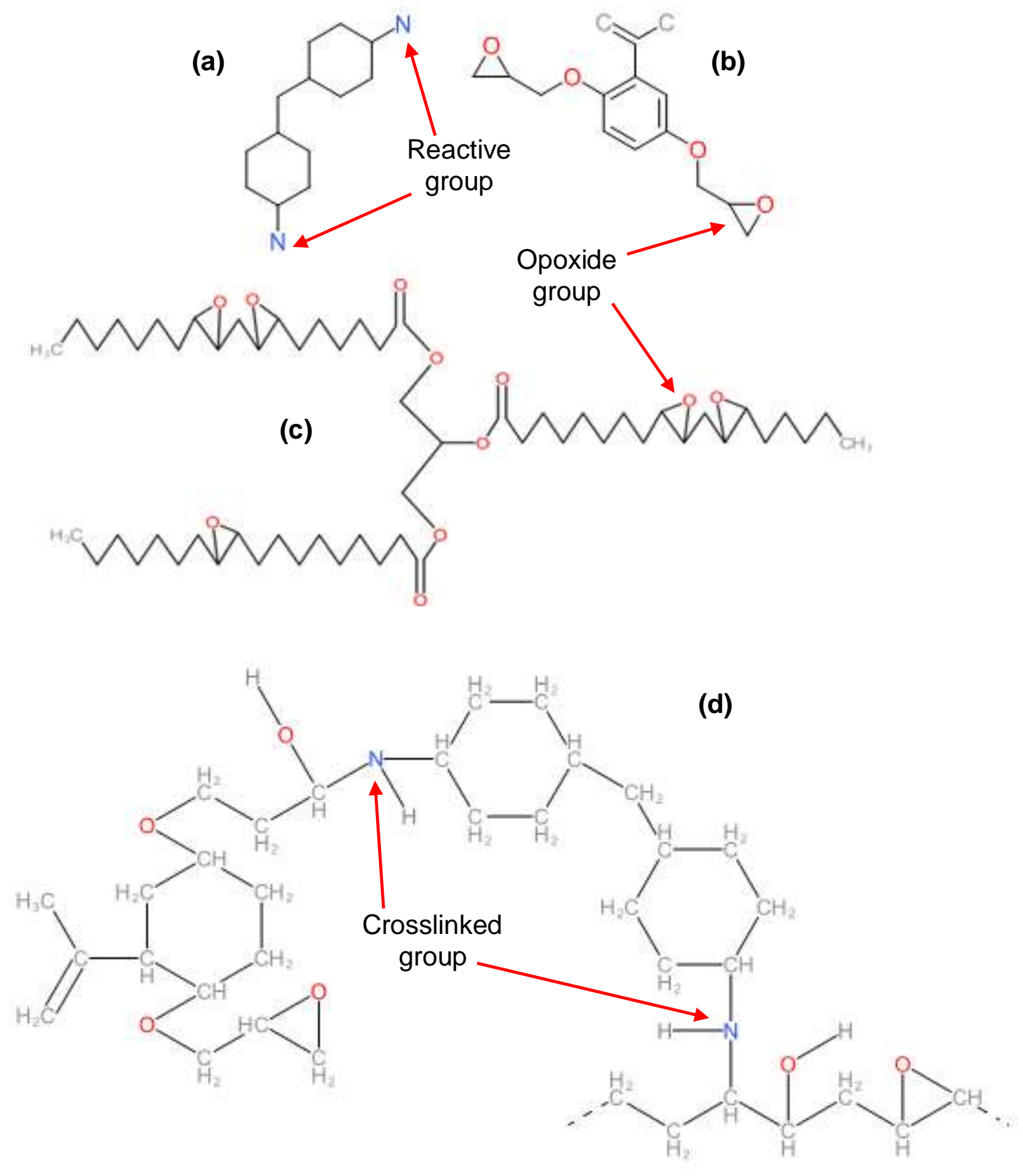

Fig. 3. Chemical structure of compounds in (a) hardener, (b) synthetic epoxy, (c) jatropha bioepoxy, (d) curing reaction of blended bio-epoxy

\section{Mechanical Performances}

Figure 4 demonstrates the tensile properties, which are tensile strength, modulus of elasticity, and elongation at break, of laminated fiber carbon with varied wt $\%$ of bio-epoxy. It was expected that bio-epoxy would decrease the tensile properties of the laminated composites. Compared to $0 \mathrm{wt} \%$ bio-epoxy, as soon as bio-epoxy was added for $18 \mathrm{wt} \%$, its tensile strength and modulus of elasticity decreased. Low modulus of elasticity revealed 
a lower rigidity attribute. The elongation at break was higher, which indicated that the specimen was more ductile when bio-epoxy was added.

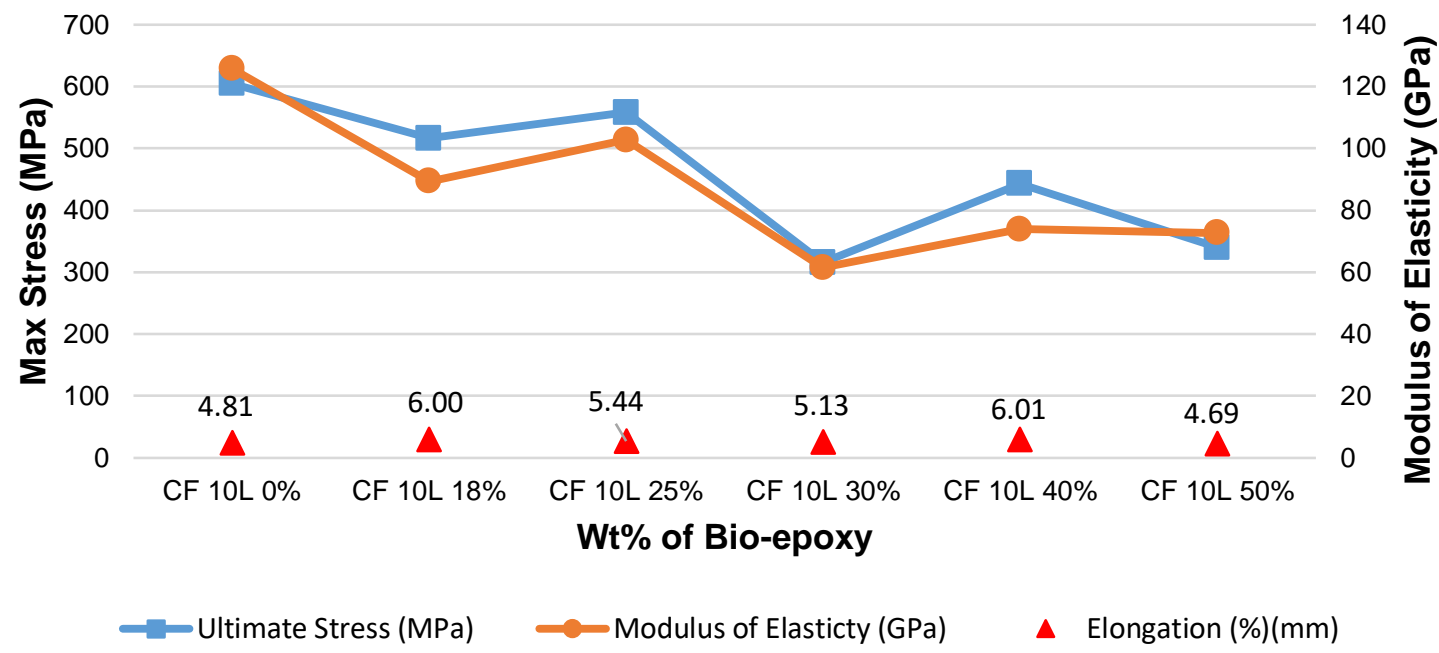

Fig. 4. Tensile performances of laminated fiber carbon with wt\% variation of bio-epoxy

As the wt $\%$ of bio-epoxy continued to vary in increment up to $50 \mathrm{wt} \%$, the tensile strength continued to decrease up to $41 \%$ for $50 \mathrm{wt} \%$ bio-epoxy. Modulus of elasticity followed the tensile strength trend as well, at up to $42 \%$ reduction for $50 \mathrm{wt} \%$. Surprisingly, $25 \mathrm{wt} \%$ and $18 \mathrm{wt} \%$ had approximately the same performances. Specimen $18 \mathrm{wt} \%$ exhibited lower tensile strength and lower modulus of elasticity than $25 \mathrm{wt} \%$, most probably due to higher void content in $18 \mathrm{wt} \%$. It had lower density, but its higher thickness explained the high void content that was formed in gasification process during fabrication. Meanwhile, for $30 \mathrm{wt} \%$ bio-epoxy, a remarkable reduction in tensile performances occurred. Therefore, $25 \mathrm{wt} \%$ bio-epoxy was a favourable blended ratio that proved to have high tensile strength, modulus of elasticity, and acceptable elongation at break.

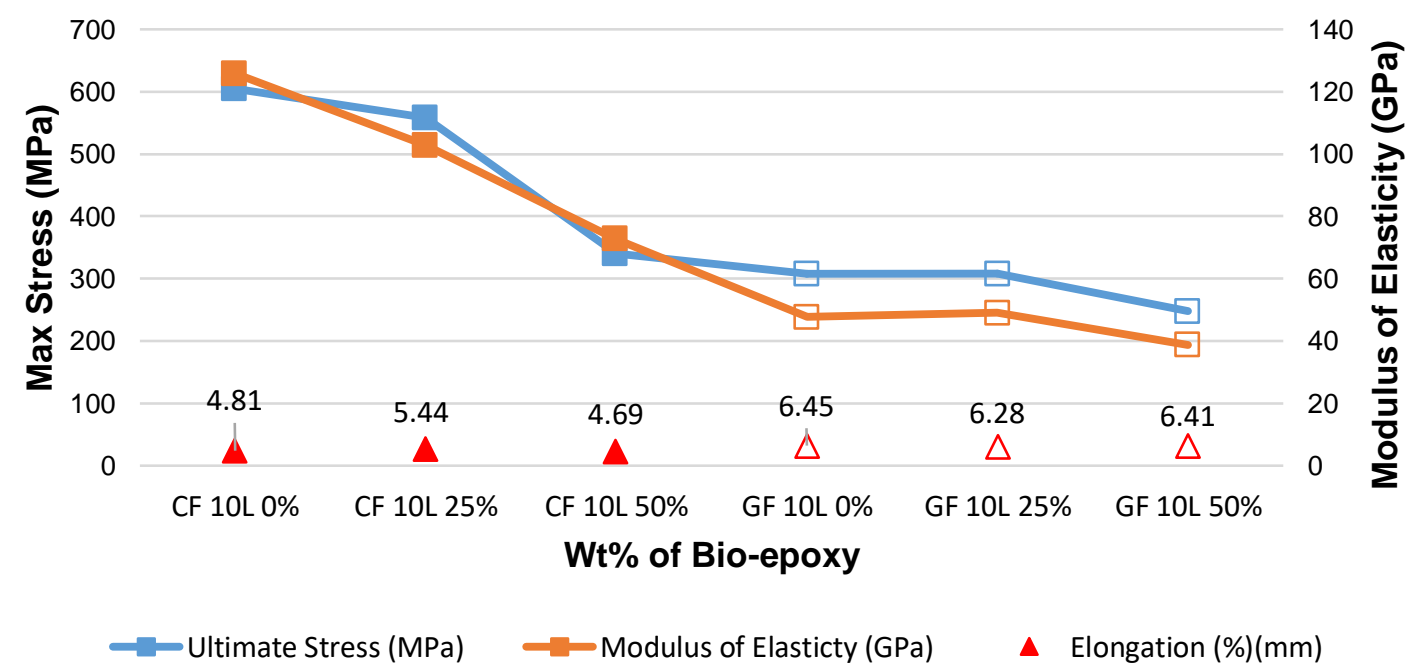

Fig. 5. Tensile performances of laminated carbon fiber and fiber glass with wt\% variation of bioepoxy 
Good tensile performances in $18 \mathrm{wt} \%$ and $25 \mathrm{wt} \%$ bio-epoxy were likely due to strong intermolecular hydrogen bonding in the laminated composite, as can be seen in the IR spectra shown in Fig. 2. This demonstrated that the performance came from a strong interfacial adhesion between fiber and bio-epoxy, which subsequently resulted in high efficiency of stress-transfer from bio-epoxy to the fibers obtained from micrography images, which is shown in Fig. 9.

Figure 5 shows a comparison of tensile strength, modulus of elasticity, and elongation at break between 10-layer laminated composites of fiber carbon (FC) and fiber glass (FG). Both were with $0 \mathrm{wt} \%, 25 \mathrm{wt} \%$, and $50 \mathrm{wt} \%$ bio-epoxy. All three results for both FC and FG showed decreased trends when bio-epoxy content increased. This was a similar trend of low performance as well as performance degradation when a natural matrix or biopolymer was used as matrix of a composite, such as polysaccharides (Jumaidin et al. 2017), bio-based epoxy (Gogoi et al. 2015), soybean bio-epoxy (Tee et al. 2016), karanja oil (Kadam et al. 2015), etc. This was because bio-epoxy had farther crosslinking distance compared to synthetic epoxy, as found by Takahashi et al. (2008), in addition to low oxirane oxygen content (OOC), which was approximately $61 \%$ as found by Ezzah (2016).

Laminated composite FG of $0 \mathrm{wt} \%$ and $25 \mathrm{wt} \%$ bio-epoxy showed almost the same tensile performances. This might have been because the specimen with $0 \mathrm{wt} \%$ contained more voids compared to $25 \mathrm{wt} \%$ as its density was higher, but thickness and fiber volume fraction were almost the same as in Figs. 21, 22, and 23. Surprisingly, the laminated composite FC with $50 \mathrm{wt} \%$ showed better performance, such as higher tensile strength, higher modulus of elasticity, and lower elongation at break, than the laminated composite FG even with $0 \mathrm{wt} \%$ bio-epoxy. Thus, it was reasonable to replace fully synthetic fiber glass composites with fiber carbon composite with $50 \mathrm{wt} \%$ bio-epoxy in any related application.

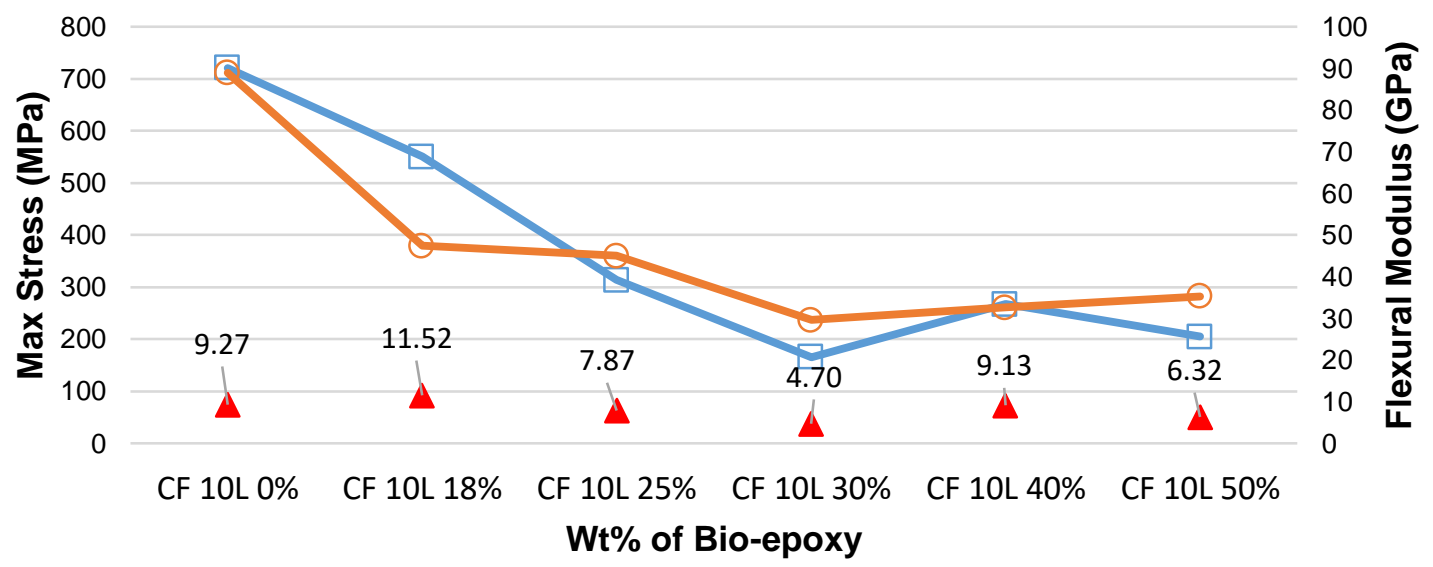

$\because$ Flexural Stress (MPa) $\quad$ Flexural Modulus (GPa) $\quad \Delta \quad \operatorname{Deformation}(\varepsilon)$

Fig. 6. Flexural performances of laminated carbon fiber with wt\% variation of bio-epoxy

Figure 6 shows flexural performances of laminated composites FC with variation of bio-epoxy of $0 \mathrm{wt} \%, 18 \mathrm{wt} \%, 25 \mathrm{wt} \%, 30 \mathrm{wt} \%, 40 \mathrm{wt} \%$, and $50 \mathrm{wt} \%$. As expected, laminated composite FC with $0 \mathrm{wt} \%$ showed the highest flexural stress and flexural modulus, followed by $18 \mathrm{wt} \%$. However, once the wt $\%$ of bio-epoxy exceeded $18 \%$, the maximum flexural stress decreased over $50 \%$. For flexural modulus, $18 \mathrm{wt} \%$ and $25 \mathrm{wt} \%$ 
bio-epoxy were almost the same even though their deformation was at $31 \%$ difference. When bio-epoxy exceeded $25 \mathrm{wt} \%$, their flexural modulus and deformation decreased. High deformation with high flexural stress meant that the composite was flexible, strong, and not easily ruptured during bending configuration.

Meanwhile, Fig. 7 shows flexural performances, such as maximum flexural stress, flexural modulus, and deformation, between laminated composite FC and FG with 0 wt $\%$, $25 \mathrm{wt} \%$, and $50 \mathrm{wt} \%$ bio-epoxy. Similar trends of decrement were seen for both reinforcements as the amount of bio-epoxy increased up to $50 \mathrm{wt} \%$. Fully synthetic composite FC had the highest performances amongst them, and $25 \mathrm{wt} \%$ was the second highest in these comparisons. The $25 \mathrm{wt} \%$ bio-epoxy was even better than fully synthetic composite FG by $14 \%$ and $70 \%$ in terms of maximum stress and flexural modulus, respectively. In contrast, both laminated composites FC and FG with 50 wt\% bio-epoxy exhibited the lowest performances with similar trends as seen in tensile results.

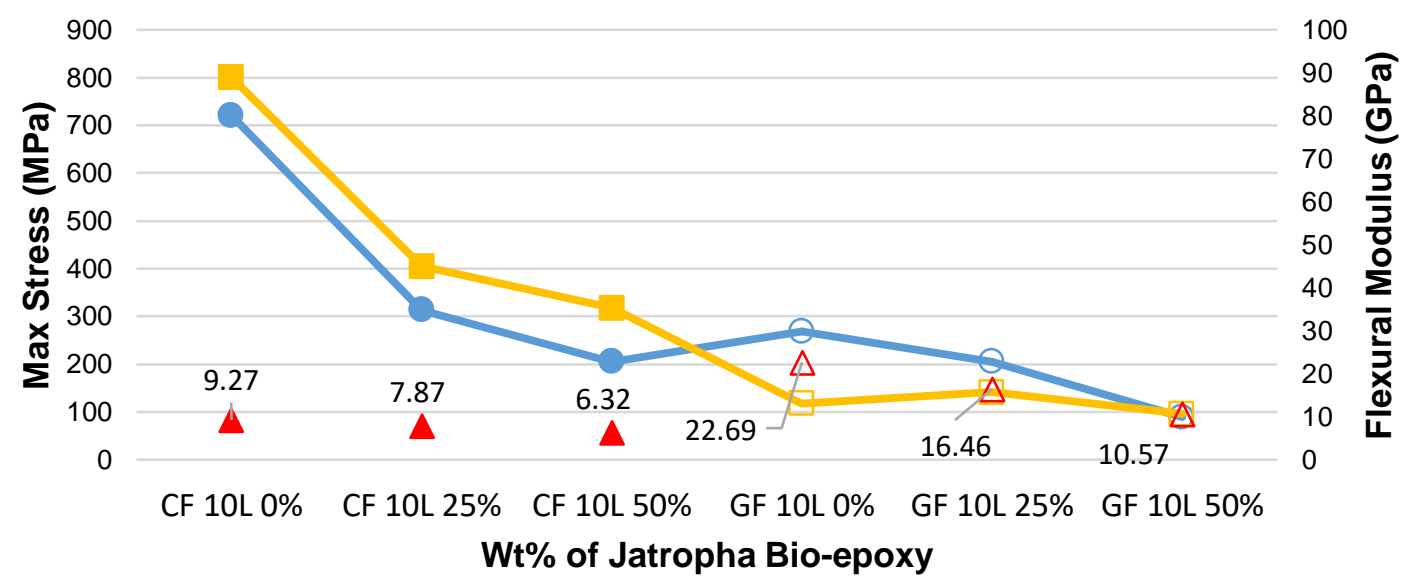

$\multimap$ Flexural Stress (MPa) $\quad-$ Flexural Modulus (GPa) $\quad \Delta \quad \operatorname{Deformation}(\varepsilon)$

Fig. 7. Flexural performances of laminated carbon fiber and glass fiber with wt\% variation of bioepoxy

Impact energy is the measure of a force acting over distance to fracture the specimen. As the striker hits the specimen, the energy is absorbed until it yields. At this point, the specimen will begin to undergo plastic deformation starting from the notch created. It continues to absorb energy and hardens the plastic zone at the notch. Fracture occurs subsequently after the specimen cannot absorb more energy. The Charpy test can determine the relative toughness of bio-epoxy with different wt\%. Low toughness materials tend to be more brittle and thus easier to break.

Figure 8 shows the impact energy versus the amount of bio-epoxy in the specimens, as indicated by the Charpy impact test. For laminated composite LC, it is normal that LC had higher impact energy compared to the pure matrix specimen as the fiber loading had improved the impact energy capability of a composite body. Because the fiber loading was constant for all specimens, only the bio-epoxy amount had varied its wt $\%$ from $0 \%, 25 \%$, $30 \%, 40 \%$, and $50 \%$. For pure epoxy specimens, the highest energy absorbed during impact was $50 \mathrm{wt} \%$ and the lowest was $0 \mathrm{wt} \%$, with $1 \%$ of difference. This indicated that higher bio-epoxy content led to slightly better energy absorption and thus more toughness in the matrix. This was due to its low brittleness compared to $0 \mathrm{wt} \%$ bio-epoxy. The tensile 
elongation at break results showed that higher amounts of bio-epoxy led to higher ductility. However, an acceptable amount of bio-epoxy needed to be chosen to avoid performance loss.

For specimens with carbon reinforcement, a similar trend of energy absorption was obtained from the impact tests, with lowest for $0 \mathrm{wt} \%$ and highest for $50 \mathrm{wt} \%$ bio-epoxy with $2.3 \%$ of difference. Moreover, the values of energy measured were a bit higher due to the presence of reinforcement inside the resin. The reinforcement played an important role in distributing impact load, which resulted in better energy absorption amounts. Furthermore, woven reinforcements also contributed to lessen the impact energy by damping the impact received throughout the continuity of its fiber length.

Because all specimens had the same woven reinforcement, nothing would differ except the amount of bio-epoxy inside the matrix. For pure resin, the failure mode of 0 $\mathrm{wt} \%, 25 \mathrm{wt} \%, 30 \mathrm{wt} \%$, and $40 \mathrm{wt} \%$ bio-epoxy involved complete breakage into two pieces, but $50 \mathrm{wt} \%$ broke but still held as one piece. A similar report on neat epoxy was obtained by Barbosa et al. (2014). The $50 \mathrm{wt} \%$ bio-epoxy was ductile and soft, which explained its ability to absorb high impact energy compared to others. Failure modes were the same for all specimens with reinforcement agent, where it started from the notch, followed by vertical interfacial fiber/matrix bonding failure, fiber breakage at the horizontal continuous fibers, matrix rupture, and then less fiber was pulled out. Furthermore, all of them were broken into two pieces. However, compared to pure matrix that failed to hold as one piece, for $50 \mathrm{wt} \%$ bio-epoxy with fiber carbon as reinforcement, the specimen was broken into two pieces.

The reinforcement acted as a barrier of the crack propagation initiated from the notch. The weave of $0^{\circ} / 90^{\circ}$ provided a balanced resistance in horizontal and vertical breakage compared to uniform woven reinforcement even though it absorbed less energy during impact. Bio-epoxy improved the energy absorbed during impact and reduced brittleness with or without reinforcement.

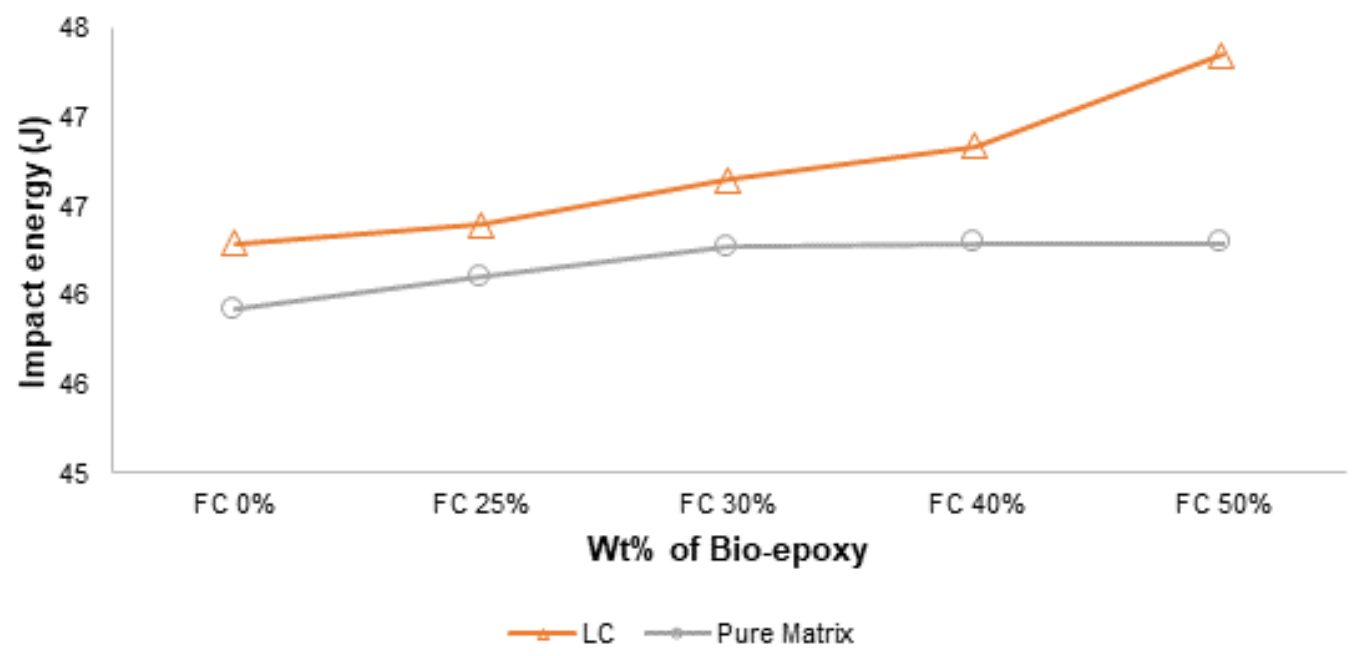

Fig. 8. Impact energy of laminated carbon fiber composite and pure matrix, both with different wt\% of bio-epoxy 


\section{Surface Morphology of Specimens with Ruptures}

Micrograph images have a good advantage in giving a detailed observation on the morphology or the physical surface of a material at a small scale that is invisible to the naked eye. Images in Fig. 9 are $0 \mathrm{wt} \%, 18 \mathrm{wt} \%, 25 \mathrm{wt} \%, 30 \mathrm{wt} \%, 40 \mathrm{wt} \%$, and $50 \mathrm{wt} \%$ bio-epoxy, with carbon fiber as reinforcement. They are images of tensile failure modes for several specimens at micrometer scale from SEM.
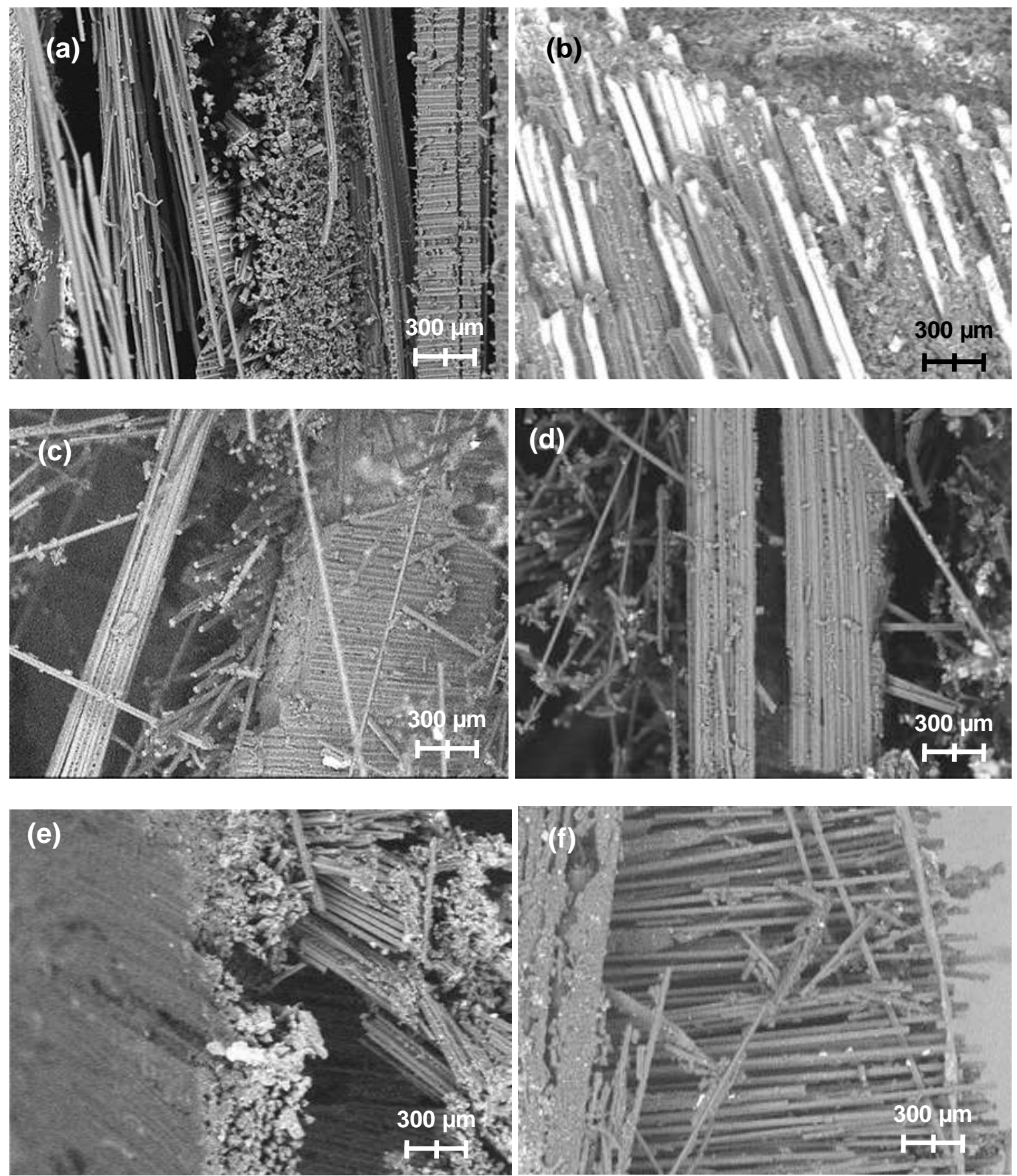

Fig. 9. Morphology of tensile failure at break: (a) 0 wt\% bio-epoxy, (b) 18 wt $\%$ bio-epoxy, (c) 25 wt\% bio-epoxy, (d) 30 wt\% bio-epoxy, (e) 40 wt\% bio-epoxy, and (f) 50 wt\% bio-epoxy 
In Fig. 9(a), which was 0 wt\% bio-epoxy, an immediate rupture of the matrix and carbon fiber was observed. This was evidence of a brutal failure during maximum tensile loading that induced breakage after maximum elongation of the specimen.

Then, in Fig. 9(b), bio-epoxy was introduced in the matrix at $18 \mathrm{wt} \%$. A similar failure mode was observed that consisted of a lot of residual matrix stuck to the ruptured fibers. In accordance with tensile strength obtained from the tensile test, these two specimens had the best tensile performances such as highest tensile strength, highest Young modulus, and lowest elongation at break. In Fig. 9(c), a failure mode for specimen with 25 $\mathrm{wt} \%$ bio-epoxy is shown. Rupture of fiber was also immediate, and an acceptable amount of residual resin at the fibers was observed. Minimal fiber pull-out was detected and 25 wt $\%$ bio-epoxy had acceptable failure mode.

Meanwhile in Fig. 9(d), which was for $30 \mathrm{wt} \%$ specimen, fiber pull out became more obvious with a noticeable number of voids between the fibers and matrix. This was attributed to the gasification phenomenon during vacuum infusion process that brought a lesser performance of the laminated composite. Residual resin at fibers also became less, which demonstrated that loading did not transfer well between fibers and matrix. In Fig. 9(e), the failure of $40 \mathrm{wt} \%$ bio-epoxy demonstrated that high amount of fiber was pulled out without much residual resin. The interfacial bonding became weak as the matrix did not adhere well. This was shown in Fig. 9(f) for specimen $50 \mathrm{wt} \%$, in which a tremendous amount of fiber pulled out and a small amount of residual resin stuck on the fibers.

\section{Thermal Behaviour}

The thermogravimetric analysis graph of pure matrices with $0 \mathrm{wt} \%, 18 \mathrm{wt} \%, 25$ $\mathrm{wt} \%, 30 \mathrm{wt} \%, 40 \mathrm{wt} \%$, and $50 \mathrm{wt} \%$ bio-epoxy and laminated composite with matrices of $0 \mathrm{wt} \%, 18 \mathrm{wt} \%, 25 \mathrm{wt} \%$, and $50 \mathrm{wt} \%$ bio-epoxy from TGA is shown in Fig. 10, and some noteworthy temperatures are tabulated in Tables 2(a) and 2(b) for pure matrices and laminated composites respectively. In general, they were two thermal degradations for pure matrices and laminated composites according to the weight loss function in the graphs. The first degradation was due to a physical transition, which was moisture evaporation with other minor volatile compounds at approximately $100{ }^{\circ} \mathrm{C}$, and the second degradation was from chemical reaction, which was decomposition of epoxy and bio-epoxy (Mincheva et al. 2013; Aung et al. 2014).

All specimens had low moisture, which was around less than $1 \%$ of their weight. Those spaces that once contained water moisture were evaporated and became voids. These voids were defects that should be minimized in a composite structure, because higher void contents led to low bonding between the composite components. This consequently leads to a lower mechanical performance, as shown in previous studies (Zafar et al. 2012; Wang et al. 2016). Synthetic epoxy is known to be hydrophobic, and jatropha bio-epoxy, which was prepared from fatty acids, was naturally hydrophobic as well. This was the reason that water moisture content was low in both specimens. The water moisture also acted as a plasticizer, which reduced the transition glass temperature of composite structure (Gibbins and Hoffman 1982; Boll et al. 1985).

The second step of thermal degradation occurred at approximately $96 \%$ at $288{ }^{\circ} \mathrm{C}$ for both the synthetic epoxy and bio-epoxy specimens. However, the bio-epoxy specimen lost its weight slightly faster than the synthetic epoxy. This indicated that between room temperature and $288^{\circ} \mathrm{C}$, the blended bio-epoxy was slightly less thermally stable than the synthetic epoxy. However, once the temperature increased and passed $288^{\circ} \mathrm{C}$, the bioepoxy was more thermally stable than the synthetic epoxy until it reached $365^{\circ} \mathrm{C}$. Referring 
to FTIR transmittance, the higher thermal stability in this region was due to more aromatic functional groups being present in the bio-epoxy compared to synthetic epoxy. Thus, additional energy was needed to overcome and dissolve the molecular bonding energy.

After this temperature, thermal degradation of the bio-epoxy continued to decrease quickly until $480{ }^{\circ} \mathrm{C}$, similar to synthetic epoxy. This was the degradation of majority aromatic functional groups that led to leftovers of char, which were less than 5\% and $10 \%$ for pure matrices of bio-epoxy and synthetic epoxy, respectively (Kuo et al. 2016). Additionally, laminated composites had residues of approximately $65 \%$ for synthetic epoxy and $70 \%$ for bio-epoxy. However, by the end of the curvature, synthetic epoxy had a residual mass than bio-epoxy. The difference in residual weight after $500{ }^{\circ} \mathrm{C}$ for synthetic epoxy and bio-epoxy was 5\%. Increasing bio-epoxy amounts provided a better thermal stability at the $288{ }^{\circ} \mathrm{C}$ to $365{ }^{\circ} \mathrm{C}$ range despite losing almost $95 \%$ of its total weight in the end compared to synthetic epoxy.

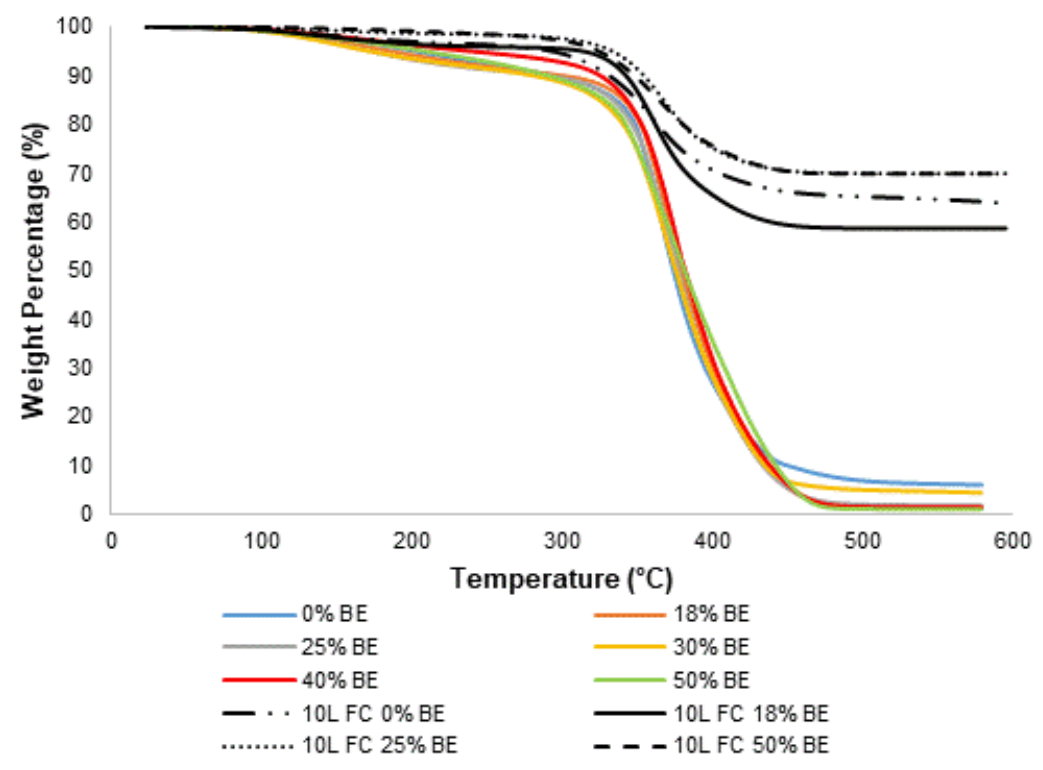

Fig. 10. TGA of pure matrices and laminated fiber carbon with variation of wt $\%$ bio-epoxy

From Fig. 11, derivative weight loss of thermal degradation revealed different weight loss rates of pure matrices and laminated composites. The residual leftover of laminated composite was higher than pure matrices due to carbon fiber reinforcement. The highest amount of bio-epoxy (50 wt\%) showed the least weight loss for both pure matrix at 0.35 and laminated composites at 0.85 , while other specimens appeared almost similar within the range of $280{ }^{\circ} \mathrm{C}$ to $480{ }^{\circ} \mathrm{C}$, which were at around 0.4 to 0.6 and 1.1 to 1.3 for pure matrix and LC respectively. However, a narrower peak was exhibited by the synthetic epoxy specimen, which revealed that weight loss occurred more quickly for synthetic epoxy than bio-epoxy. Additionally, broader curvatures occurred for all bio-epoxy specimens, which revealed a better thermal stability behaviour compared to synthetic epoxy in the same temperature range $\left(280{ }^{\circ} \mathrm{C}\right.$ to $\left.480{ }^{\circ} \mathrm{C}\right)$. 


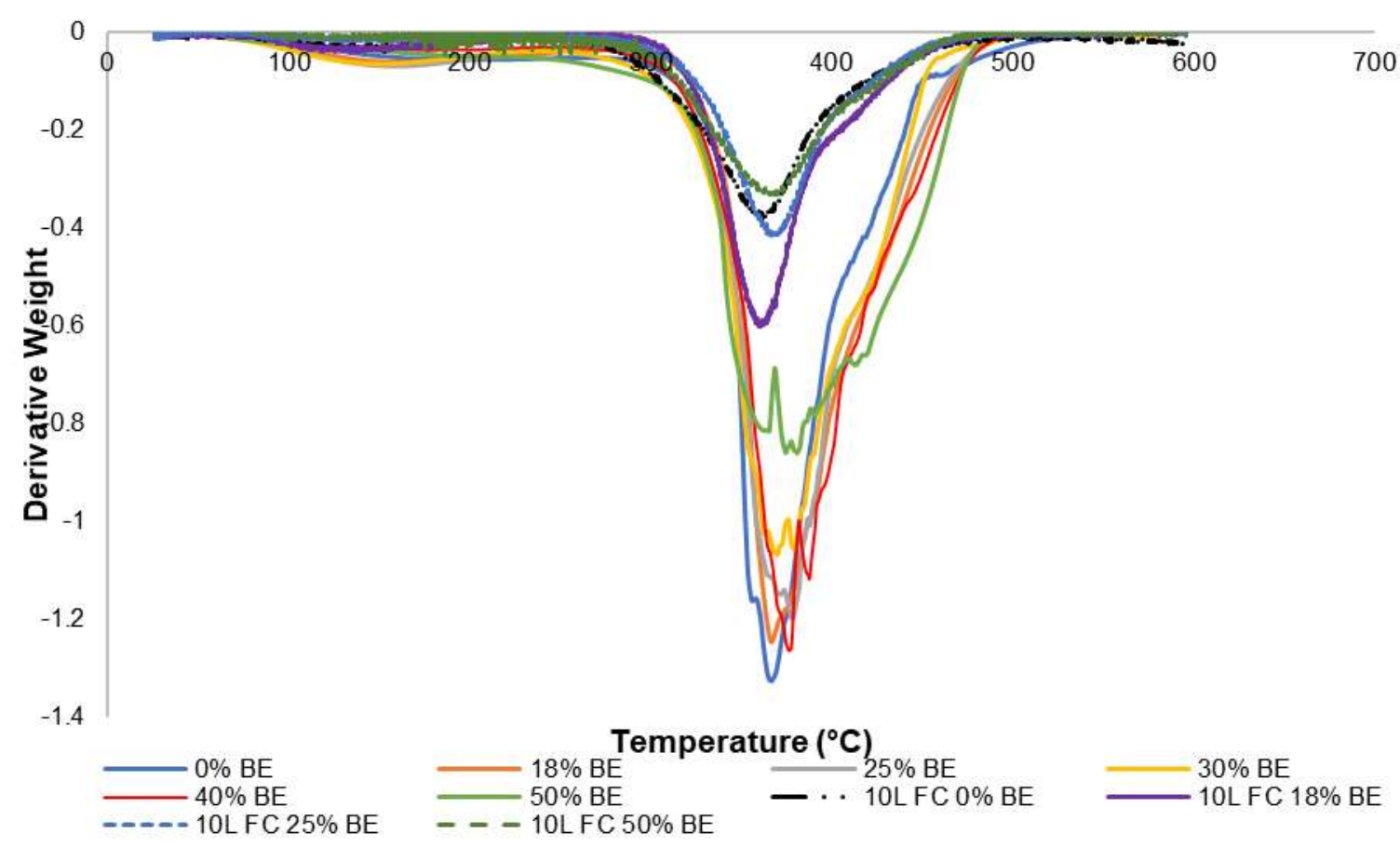

Fig. 11. Weight derivative of pure matrices and laminated fiber carbon with wt\% variation of bioepoxy content

The statistic heat-resistance index $\left(T_{\mathrm{s}}\right)$ is an index for evaluating thermal stability of cured resin and was determined from the temperature at $5 \%$ weight loss $\left(T_{\mathrm{d} 5}\right)$ and $30 \%$ weight loss $\left(T_{\mathrm{d} 30}\right)$ of the specimens, which were obtained from the TGA curves as in Table 2(a) and 2(b) for pure matrices and carbon fiber laminated composite respectively. The $T_{\mathrm{s}}$ index temperature was calculated from Eq. 1. In the present study, all specimens, consisting of $0 \%, 18 \%, 25 \%, 30 \%, 40 \%$, and $50 \%$ of bio-epoxy, lost $30 \%$ of their weight at below $350{ }^{\circ} \mathrm{C}$ and $5 \%$ at approximately $100{ }^{\circ} \mathrm{C}$.

Table 2(a). Thermal Degradation at 5\% and 30\% for Specimen of Pure Matrices

\begin{tabular}{|c|c|c|c|c|c|c|}
\hline $\begin{array}{c}\text { Specimens of Pure } \\
\text { matrices }\end{array}$ & $\begin{array}{c}0 \mathrm{wt} \% \\
\mathrm{BE}\end{array}$ & $\begin{array}{c}18 \mathrm{wt} \% \\
\mathrm{BE}\end{array}$ & $\begin{array}{c}25 \mathrm{wt} \% \\
\mathrm{BE}\end{array}$ & $\begin{array}{c}30 \mathrm{wt} \% \\
\mathrm{BE}\end{array}$ & $\begin{array}{c}40 \mathrm{wt} \% \\
\mathrm{BE}\end{array}$ & $\begin{array}{c}50 \mathrm{wt} \% \\
\mathrm{BE}\end{array}$ \\
\hline $\mathrm{Td} 5\left({ }^{\circ} \mathrm{C}\right)$ & 198 & 185 & 185 & 189 & 238 & 208 \\
\hline $\operatorname{Td} 30\left({ }^{\circ} \mathrm{C}\right)$ & 352 & 363 & 359 & 360 & 367 & 357 \\
\hline Residual Weight $(\%)$ & 6 & 1 & 2 & 4 & 1 & 1 \\
\hline
\end{tabular}

Table 2(b) for Specimen of Carbon Fiber Laminated Composites with Different Epoxy/Bio-epoxy wt\%

\begin{tabular}{|c|c|c|c|c|}
\hline $\begin{array}{c}\text { Specimens of } 10 \mathrm{~L} \\
\text { carbon fibre LC }\end{array}$ & $\begin{array}{c}0 \mathrm{wt} \% \\
\mathrm{BE}\end{array}$ & $\begin{array}{c}18 \mathrm{wt} \% \\
\mathrm{BE}\end{array}$ & $\begin{array}{c}25 \mathrm{wt} \% \\
\mathrm{BE}\end{array}$ & $\begin{array}{c}50 \mathrm{wt} \% \\
\mathrm{BE}\end{array}$ \\
\hline $\mathrm{Td} 5\left({ }^{\circ} \mathrm{C}\right)$ & 293 & 313 & 325 & 325 \\
\hline $\mathrm{Td} 30\left({ }^{\circ} \mathrm{C}\right)$ & 404 & 383 & 460 & 464 \\
\hline Residual Weight $(\%)$ & 64 & 59 & 70 & 70 \\
\hline
\end{tabular}


Figure 12 presents comparison $T_{\mathrm{g}}$ onset, char formation temperature after TGA finished and $T_{\mathrm{s}}$ from TG analysis. In Fig. 12(a), the values of $T_{\mathrm{s}}$ were comparable for 0 $\mathrm{wt} \%, 18 \mathrm{wt} \%, 25 \mathrm{wt} \%$, and $30 \mathrm{wt} \%$ bio-epoxy, which were $142{ }^{\circ} \mathrm{C}, 143{ }^{\circ} \mathrm{C}, 142{ }^{\circ} \mathrm{C}$, and $143{ }^{\circ} \mathrm{C}$, respectively. At $40 \mathrm{wt} \%$ and $50 \mathrm{wt} \%$ bio-epoxy, their $T_{\mathrm{s}}$ increased up to $155{ }^{\circ} \mathrm{C}$ and $145{ }^{\circ} \mathrm{C}$, respectively. Similar patterns occurred for laminated composites as shown in Fig. 12(b), which were comparable for $0 \mathrm{wt} \%$ and $18 \mathrm{wt} \%$, and higher $T_{\mathrm{s}}$ values were found for $25 \mathrm{wt} \%$ and $50 \mathrm{wt} \%$ bio-epoxy. Adding bio-epoxy in the matrix increased $T_{\mathrm{s}}$ of the composite, which was contrary to research by Kuo et al. (2014) and Deng et al. (2015), who found $T_{\mathrm{s}}$ was comparable with the addition of lignin bio-based epoxy, karanja oil based epoxy, and bio-mass based epoxy (Kuo et al. 2014; Deng et al. 2015; Kadam et al. 2015).

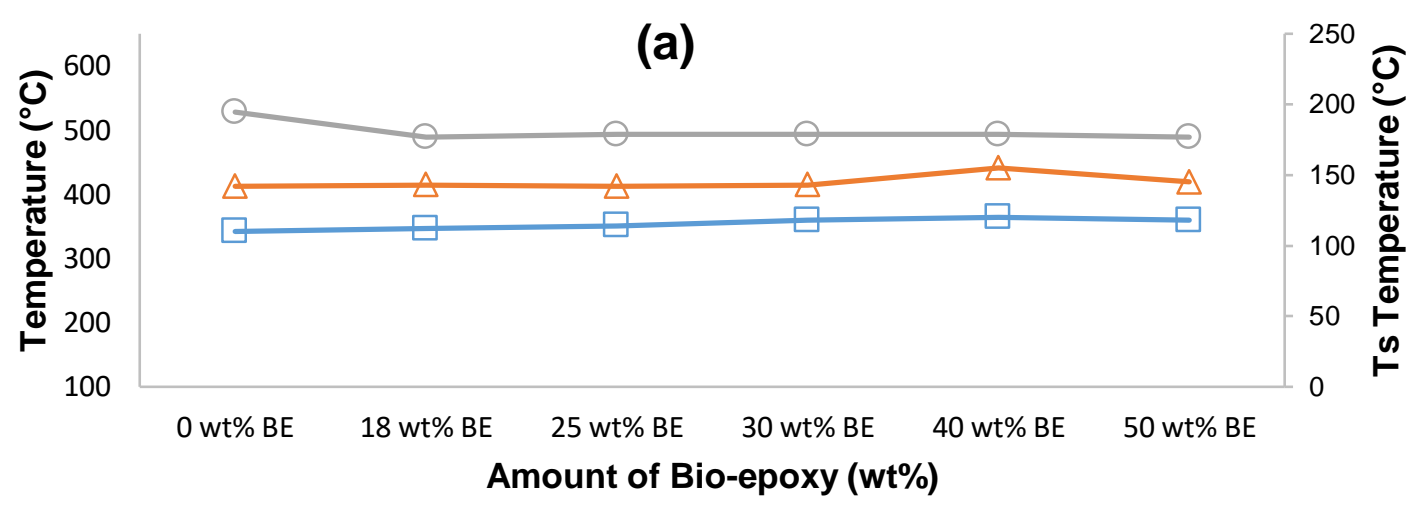

$\multimap$ Char Temperature $\left({ }^{\circ} \mathrm{C}\right) \quad \square \operatorname{Tg}$ Onset $\left({ }^{\circ} \mathrm{C}\right) \quad \triangle$ Heat-resistant Index (Ts)

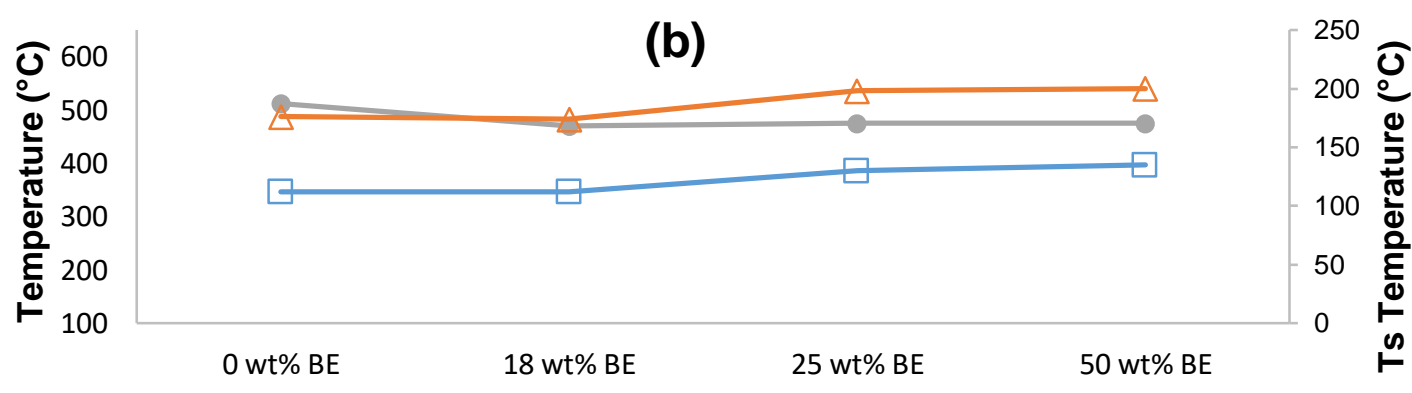

Amount of Bio-epoxy (wt\%)

$\longrightarrow$ Char Temperature $\left({ }^{\circ} \mathrm{C}\right) \quad \square$ T Onset $\left({ }^{\circ} \mathrm{C}\right) \quad \triangle$ Heat-resistant Index (Ts)

Fig. 12. $T_{\mathrm{g}}$ onset temperature, Char formation temperature and Ts temperature for (a) pure matrices with wt\% variation of bio-epoxy content. (b) for laminated carbon fiber composites with wt $\%$ variation of bio-epoxy content

Another study successfully improved $T_{\mathrm{S}}$ of a synthetic epoxy by adding sulfonic groups into the matrix (Chiu et al. 2008). However, both these index values are considered medium-range index values (Bibiao et al. 2001). The heat-resistant index was improved, which was likely due to higher amounts of aromatic ring groups and carboxyl groups in the bio-epoxy that provided a good thermal stability property to the material (Li et al. 2014). Temperature at char formation was the highest for synthetic epoxy. However, it was 
comparable for all ratios of bio-epoxy specimens. Residual weight of pure matrix bioepoxy was less than $4 \%$, while synthetic epoxy pure matrix was $6 \%$. Additionally, residual weights for laminated composite were comparable, which were from $59 \%$ to $70 \%$. It was possible to conclude that reinforcement had increased total thermal stability compared to pure matrices.

The results of DSC can be seen in the thermograms in Fig. 13. One of these thermograms was exothermic, as the sensor captured the heat released by the specimen. This was to determine thermal behaviour of matrices and laminated composite with bioepoxy when temperature increased over time. Through observing the changes in heat capacity $\left(C_{\mathrm{p}}\right)$, the authors could obtain interesting characteristics such as glass transition $\left(T_{\mathrm{g}}\right)$ temperature, onset and completion of cure, heat of cure, maximum rate of cure, and percent of cure, as well as heat capacity. Normally, $T_{\mathrm{g}}$ of a cured resin depends on molecular structure that develops during curing, which is driven by cross-link density, stiffness of polymer backbone, and intermolecular interactions (Pawar et al. 2016).

Overall, DSC curvatures of pure resin had similar trends with three total peaks, as presented in Fig. 13. The first peak was the $T_{\mathrm{g}}$, the second peak was the extended curing process, and the last peak was the decomposition. There was only one peak of $T_{\mathrm{g}}$, which showed that bio-epoxy blended well with synthetic epoxy, even though the two epoxies were from different sources. Meanwhile, DSC curvatures for bio-epoxy laminated composite LC had two peaks. The first peak was $T_{\mathrm{g}}$, and the second peak was the extended curing process. The difference in curvatures of bio-epoxy and LC was the amplitude of the peak and the broadness of the peak. Specimens of LC had lower and broader peaks due to the presence of fiber carbon reinforcement and smaller numbers of matrices. Higher peaks in the second peak meant that more energy was used to break the molecules, and thus more cured resin was present in bio-epoxy compared to synthetic epoxy.

The first onset drop of pure matrices occurred at approximately $65{ }^{\circ} \mathrm{C}$ for synthetic epoxy, approximately $62{ }^{\circ} \mathrm{C}$ for $18 \mathrm{wt} \%$ and $25 \mathrm{wt} \%$ bio-epoxy, and approximately $58{ }^{\circ} \mathrm{C}$ for $30 \mathrm{wt} \%, 40 \mathrm{wt} \%$, and $50 \mathrm{wt} \%$ bio-epoxy. These points were the glass transition $\left(T_{\mathrm{g}}\right)$ temperature for their respective specimens, as can be seen in Fig. 14. These drops were endothermic, which exhibited the glass transition temperature as the starting point for the energy required to change the molecular structure inside the epoxy and the bio-epoxy from a low energy state to a higher energy state. This reaction changed the state of the matrices from a solid state to a rubbery state. The synthetic epoxy had slightly higher $T_{\mathrm{g}}$ compared to bio-epoxy, most likely due to epoxy groups in the bio-epoxy that were the internal oxiranes, which were situated in the middle of fatty acid chains (Rwawiire et al. 2015; Pawar et al. 2016). The unfortunate location of oxirane led to decreased reactivity compared to end or terminal oxirane. Nevertheless, a longer curing time with proper heat would overcome this phenomenon. Similar trends of lower $T_{\mathrm{g}}$ in bio-epoxy compared to synthetic epoxy were found in other studies as well (Kadam et al. 2015). Then, at approximately $230{ }^{\circ} \mathrm{C}$, synthetic epoxy had the second peak, which was an exothermic peak due to extended curing of remaining oxirane and radicals from the hardener. Additionally, all specimens with bio-epoxy reacted earlier for an extended curing process, which was approximately $200{ }^{\circ} \mathrm{C}$. In this peak, all remaining oxirane and crosslinkers would settle each other, thus completing the curing, thus it is called self-catalyzation.

Right after the second endothermic reaction, there was a high peak in the exothermic curve for pure matrix specimens. These peaks were at approximately $260{ }^{\circ} \mathrm{C}$ for synthetic epoxy and greater than $265{ }^{\circ} \mathrm{C}$ for bio-epoxy. It was believed that the heating process might start to change the molecular structure inside the synthetic epoxy and the 
bio-epoxy. This was verified with a thermogram from the TGA analysis in Fig. 10. As the temperature reached $350{ }^{\circ} \mathrm{C}$, both epoxy and bio-epoxy began to lose weight rapidly. This indicated that epoxy and bio-epoxy started to decompose into the environment because the epoxy and bio-epoxy were thermoset, which meant they had no melting phase.

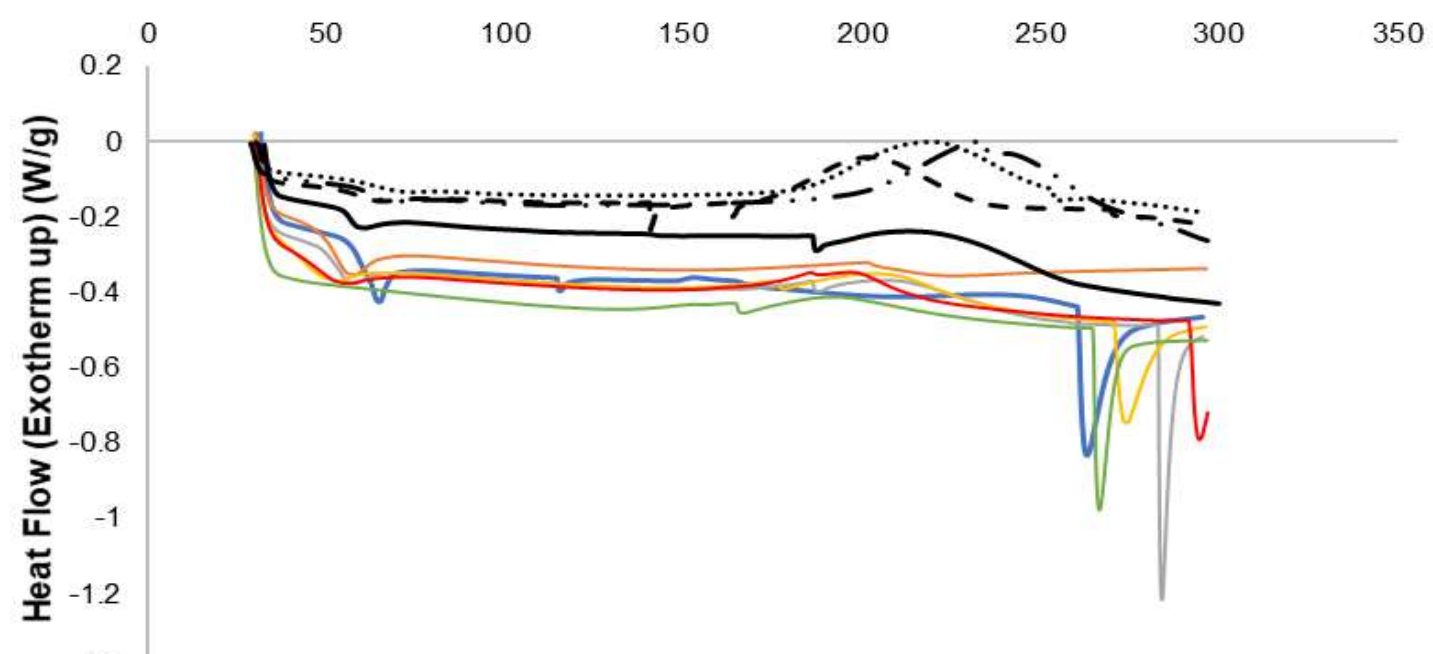

Temperature $\left({ }^{\circ} \mathrm{C}\right)$

$-0 \% \mathrm{BE}-18 \% \mathrm{BE}-25 \% \mathrm{BE}-30 \% \mathrm{BE}-40 \% \mathrm{BE}$
$-50 \% \mathrm{BE}-\cdots 0 \% \mathrm{FC}-18 \% \mathrm{FC} \cdots \cdots . \cdots 25 \% \mathrm{FC}--50 \% \mathrm{FC}$

Fig. 13. DSC curvature of pure matrices and laminated FC with varying amount of bio-epoxy

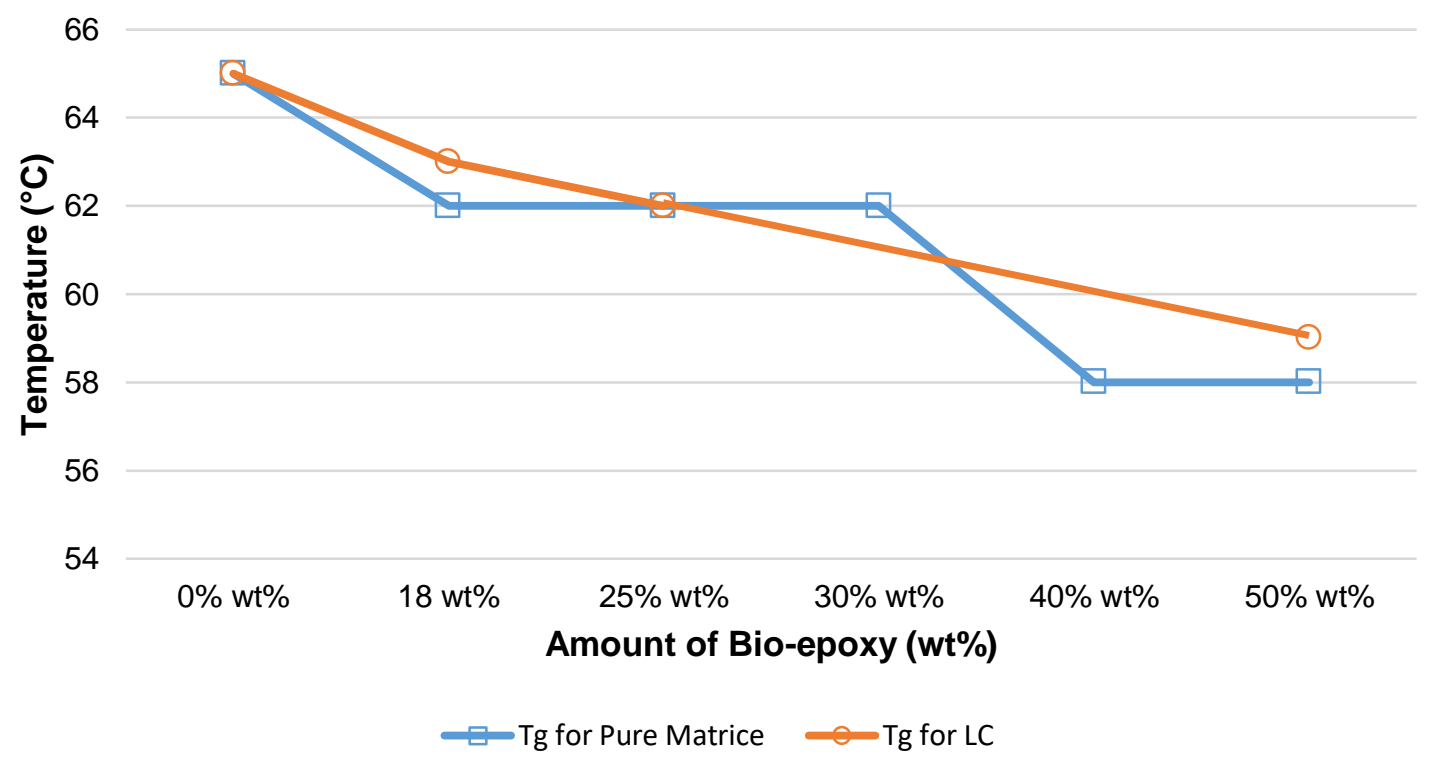

Fig. 14. Comparison of $\mathrm{Tg}$ value of pure matrix and carbon fiber $\mathrm{LC}$ specimens from the curvatures of DSC.

The storage modulus in viscoelastic polymer represents the elastic portion or the solid-like behaviour of the material. The storage modulus $\left(E^{\prime}\right)$ or dynamic modulus, typically related to the Young's modulus, is often associated with stiffness of a material 
and is used as a way to determine how stiff or flimsy a sample is (Saba et al. 2016). The $E^{\prime}$ 'is regarded as the tendency/ability of a material to store energy applied to it for future purposes. In Fig. 15 the storage modulus can be divided into three regions: the glassy region (before the dashed lines), the glass transition region (encircled area), and the rubbery region (after the double dotted line) (Saba et al. 2016). Normally, as specimens were heated in the glassy state, the storage modulus value is decreased, which indicates that more molecular movement is occurring in the polymer network. In the glassy region, the specimen is normally hard, rigid, and solid, while in transition and the rubbery region, it is more flexible, soft, and amorphous. Through looking at the shape of the curves, the specimen with bio-epoxy experienced a higher decrease rate of storage modulus values in the transition region compared to synthetic epoxy. Eventually, all specimens were in rubbery state after the temperature exceeded $100{ }^{\circ} \mathrm{C}$.

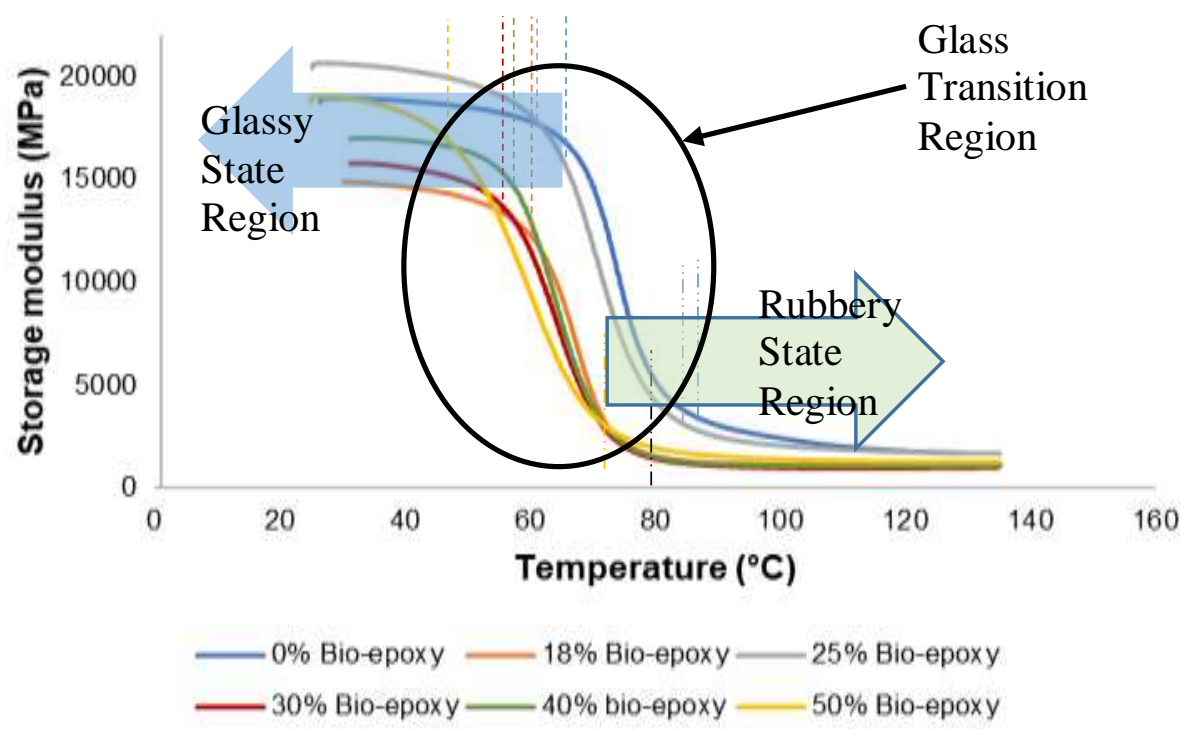

Fig. 15. Storage modulus of LC with variation of wt\% bio-epoxy

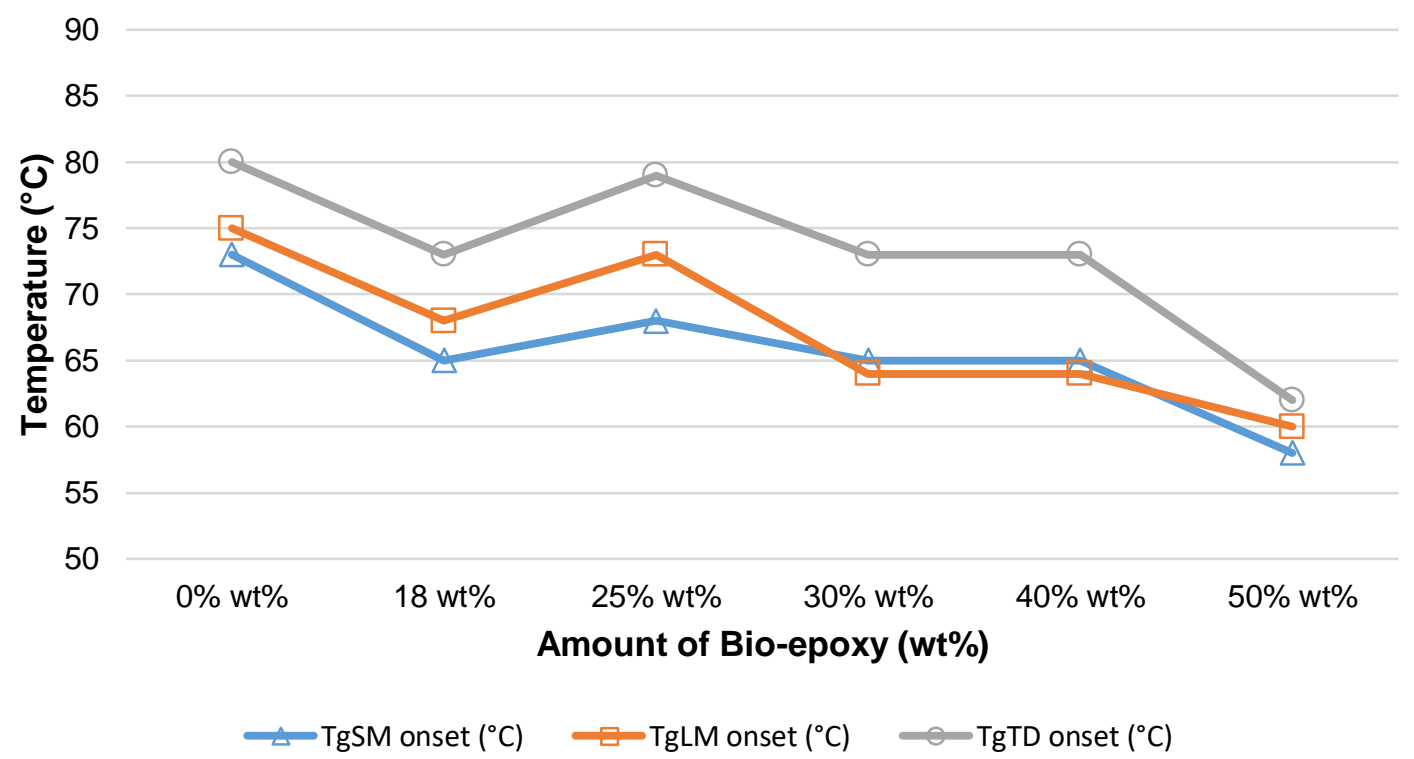

Fig. 16. Tg variation of carbon fiber LC with different wt\% bio-epoxy from curvatures of Tan Delta, Loss Modulus and Storage modulus 
The specimens with bio-epoxy also had a shorter temperature range for its glassy state. The temperature at onset of rapid decrease in storage modulus was the transition glass temperature $\left(T_{\mathrm{gSM}}\right)$. The values for these were $73{ }^{\circ} \mathrm{C}, 65^{\circ} \mathrm{C}, 68{ }^{\circ} \mathrm{C}, 65^{\circ} \mathrm{C}, 65^{\circ} \mathrm{C}$, and 58 ${ }^{\circ} \mathrm{C}$ for the $0 \mathrm{wt} \%, 18 \mathrm{wt} \%, 25 \mathrm{wt} \%, 30 \mathrm{wt} \%, 40 \mathrm{wt} \%$, and $50 \mathrm{wt} \%$ of bio-epoxy, respectively. $T_{\mathrm{g}}$ was reduced by up to $11 \%$ when $50 \mathrm{wt} \%$ bio-epoxy was added, which indicated that the trends of $T_{\mathrm{g}}$ continued to decrease when bio-epoxy amount was increased as observed in Fig. 16.

The loss modulus in viscoelastic polymer represents the viscous portion or liquidlike behaviour of the thermosets. Loss modulus ( $\left.E^{\prime \prime}\right)$, or dynamic loss modulus, is a viscous response of materials and is regarded as the tendency of materials to dissipate energy applied to it. The dynamic loss modulus is often associated with "internal friction" and is sensitive to different kinds of molecular motions, transitions, relaxation processes, morphology, and other structural heterogeneities (Saba et al. 2016). As a polymer becomes more viscous, it will begin to lose its loss modulus capability. Figure 17 shows the loss modulus curve as a function of temperature. Synthetic epoxy specimens had the highest temperature peak, which was $75^{\circ} \mathrm{C}$, while bio-epoxy specimens had $68{ }^{\circ} \mathrm{C}, 73{ }^{\circ} \mathrm{C}, 64{ }^{\circ} \mathrm{C}$, $64{ }^{\circ} \mathrm{C}$, and $60{ }^{\circ} \mathrm{C}$ for $18 \mathrm{wt} \%, 25 \mathrm{wt} \%, 30 \mathrm{wt} \%$, $40 \mathrm{wt} \%$, and $50 \mathrm{wt} \%$, respectively. These were the glass transition $\left(T_{\mathrm{gLM}}\right)$ temperatures that loss modulus could provide. For the specimens with bio-epoxy, loss modulus started to increase remarkably as soon as the specimen was heated, compared to the specimen with synthetic epoxy. Furthermore, the width of the peak curve from the specimen with bio-epoxy had a base line that was slightly broader than the synthetic epoxy.

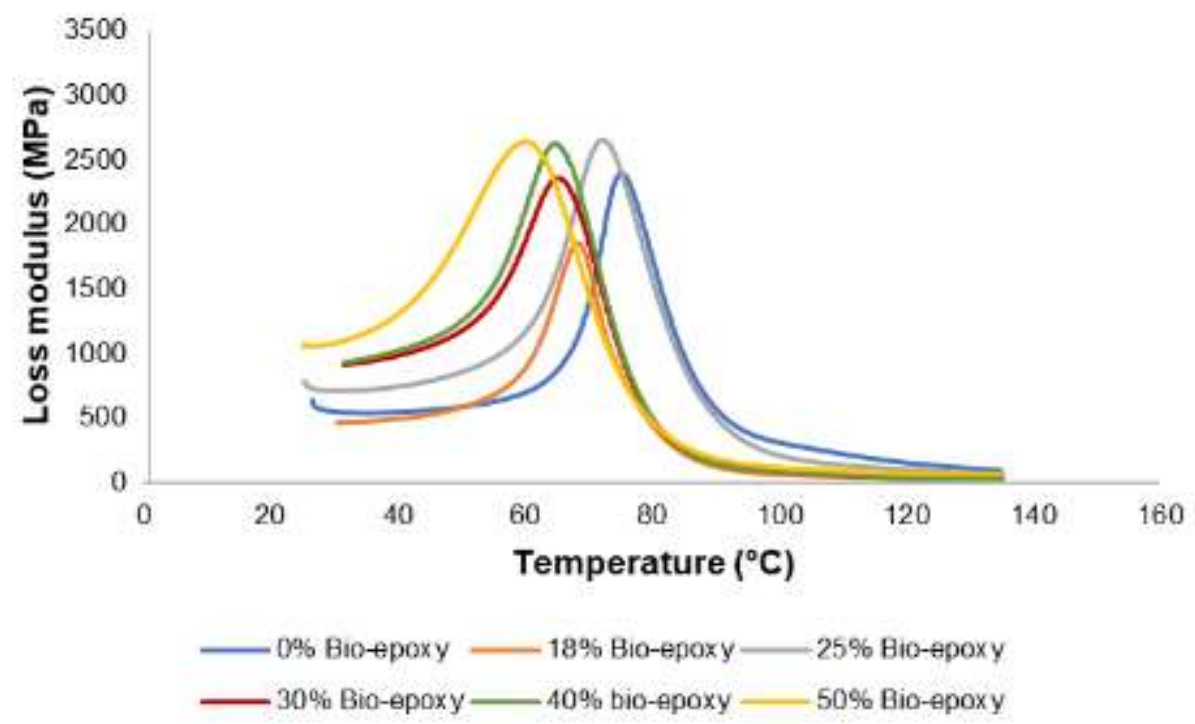

Fig. 17. Loss modulus of LC with variation of wt\% bio-epoxy

The ratio of loss modulus over storage modulus $\left(E^{\prime \prime} / E^{\prime}\right)$ is the $\tan \delta$ in Fig. 18. The peak maximum of the $\tan \delta$ curvature was the transition glass temperature according to tan $\delta$ ( $\left.T_{\mathrm{gTD}}\right)$ of a polymer. The highest $T_{\mathrm{gTD}}$ was $80{ }^{\circ} \mathrm{C}$ for synthetic epoxy, followed by $73{ }^{\circ} \mathrm{C}$, $79{ }^{\circ} \mathrm{C}, 73{ }^{\circ} \mathrm{C}, 73{ }^{\circ} \mathrm{C}$, and $62{ }^{\circ} \mathrm{C}$ for $18 \mathrm{wt} \%, 25 \mathrm{wt} \%, 30 \mathrm{wt} \%, 40 \mathrm{wt} \%$, and $50 \mathrm{wt} \%$ bioepoxy, respectively. In addition, the width of the tan $\delta$ peak curvature might suggest the degree of homogeneity of the network. Paramarta and Webster (2016) and Pan et al. (2011) also found the same pattern for bio-based thermosets, whereby a broader peak and a 
narrower peak was due to a higher catalyst amount in the blended polymer. The broader peak of $\tan \delta$ meant less homogeneity (Pan et al. 2011). Increasing the fiber/resin interfacial bonding resulted in a reduction in damping ability because the mobility of molecular chains at the fiber/resin interface was decreased. A lower energy loss $\left(E^{\prime \prime}\right)$ led to a higher $\tan \delta$. The damping factor was related to the molecular movements and viscoelasticity properties of the material. In addition, certain defects could contribute towards damping, such as crystal dislocations, grain boundaries, phase boundaries, and molecule interface.

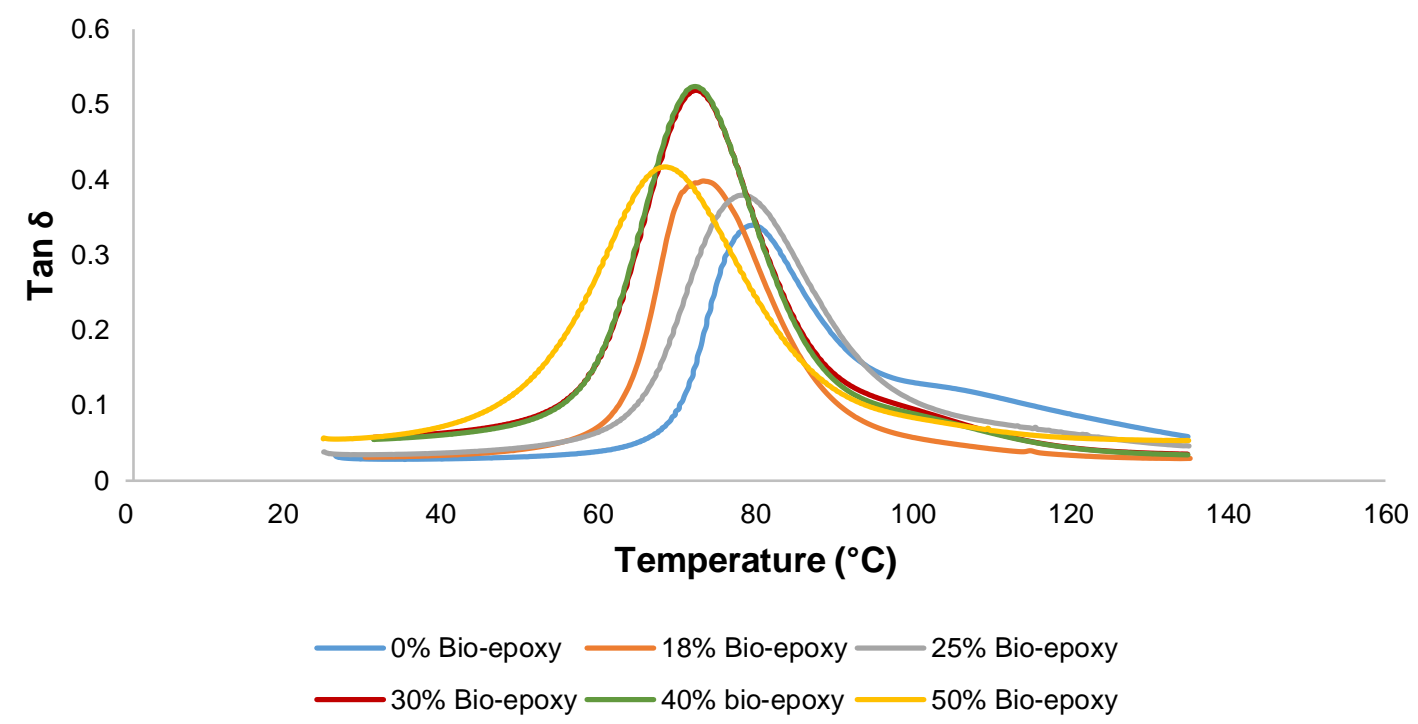

Fig. 18. Tan $\delta$ relation of LC with variation of wt\% bio-epoxy

\section{Physical Properties}

The images in Fig. 19(a) and 19(b) are uncured bio-epoxy, while the rest of Fig. 19 are images of cured bio-epoxy. The uncured pure synthetic epoxy was clear and transparent, as shown in Fig. 19(a), while the bio-epoxy was clear and transparent but with a yellowish hue.

The synthetic epoxy was stirred mechanically with bio-epoxy per appropriate amount so that the appearance of bio-epoxy could be observed. As $18 \mathrm{wt} \%$ bio-epoxy was introduced, appearance of the matrix changed from transparent to translucent, which only permitted a certain amount of light to pass through it. When the amount of bio-epoxy was increased to $25 \mathrm{wt} \%$ and $30 \mathrm{wt} \%$, the matrix became less translucent, meaning that lesser amounts of light could pass through it. However, for $40 \mathrm{wt} \%$ and $50 \mathrm{wt} \%$ bio-epoxy, the blended matrix became transparent but with a yellowish hue.

As reported from a previous experiment, a yellowish hue was due to traces of unsaturated fatty acids, such as dimers of oleic acid-oleic acid and oleic acid-linoleic acid in the blended matrix, and high molecular weight coloured compounds contributed to the final colour of an oil (Ooi et al. 2000). This was due to the size of molecules and crystalline/amorphous structure inside the cured epoxy. Small size molecules allowed light to pass through it compared to bigger molecules that scattered light away (Groover 2010).

As the bio-epoxy thickened, it became more opaque, as demonstrated in Fig. 19. This was attributed to the crystalline structure being higher in bio-epoxy compared to synthetic epoxy. 


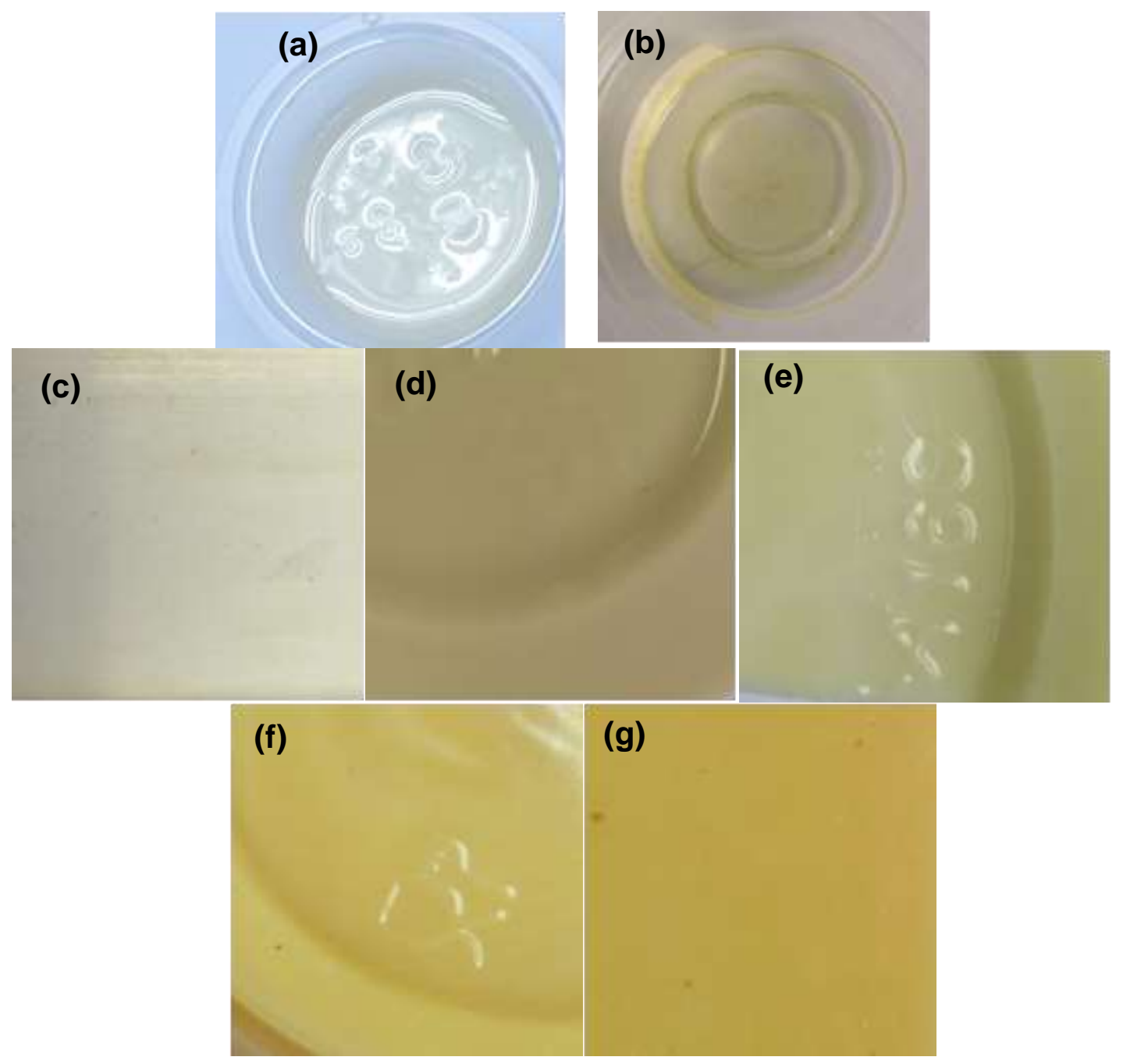

Fig. 19. Appearance of uncured and cured matrices with certain weight percentage of bio-epoxy: (a) uncured synthetic epoxy, (b) uncured bio-epoxy, (c) cured 0\% bio-epoxy, (d) cured $25 \%$ bioepoxy, (e) cured 30\% bio-epoxy, (f) cured 40\% bio-epoxy, and (g) cured 50\% bio-epoxy

As shown in Fig. 20, the composite could be categorized as either being shiny with a reflective surface or matte with a less reflective finishing. Both types of finishing had advantages and disadvantages according to their application, such as controlling the thermal consequences by solar radiation as used in NASA devices and equipment such as garments, spacesuits, etc. (NASA 1975).

Figure 21 shows the density of bio-epoxy with blended percentages from $0 \mathrm{wt} \%$, $18 \mathrm{wt} \%, 25 \mathrm{wt} \%, 30 \mathrm{wt} \%, 40 \mathrm{wt} \%$, and $50 \mathrm{wt} \%$ with and without reinforcement. In Fig. 21(a), the theoretical density of pure resin versus experimental pure resin revealed an opposite trend that was still comparable, as the difference was minimal. The experimental density was almost the same for $0 \%, 18 \%$, and $25 \%$. However, as the wt $\%$ of bio-epoxy surpassed $30 \%$, its density began to slightly decrease up to $15 \%$ for $50 \mathrm{wt} \%$ bio-epoxy. Figure 21(b) shows the experimental density of laminated composite of bio-epoxy with 10 layers of fiber carbon reinforcement. As the wt $\%$ of bio-epoxy increased from $0 \mathrm{wt} \%$ to $50 \mathrm{wt} \%$, the decrement trend was almost similar to experimental pure resin. However, $0 \mathrm{wt} \%$ and $25 \mathrm{wt} \%$ were comparable. As the wt $\%$ of bio-epoxy surpassed $30 \%$, the density began to decrease as well, up to $5 \%$. 

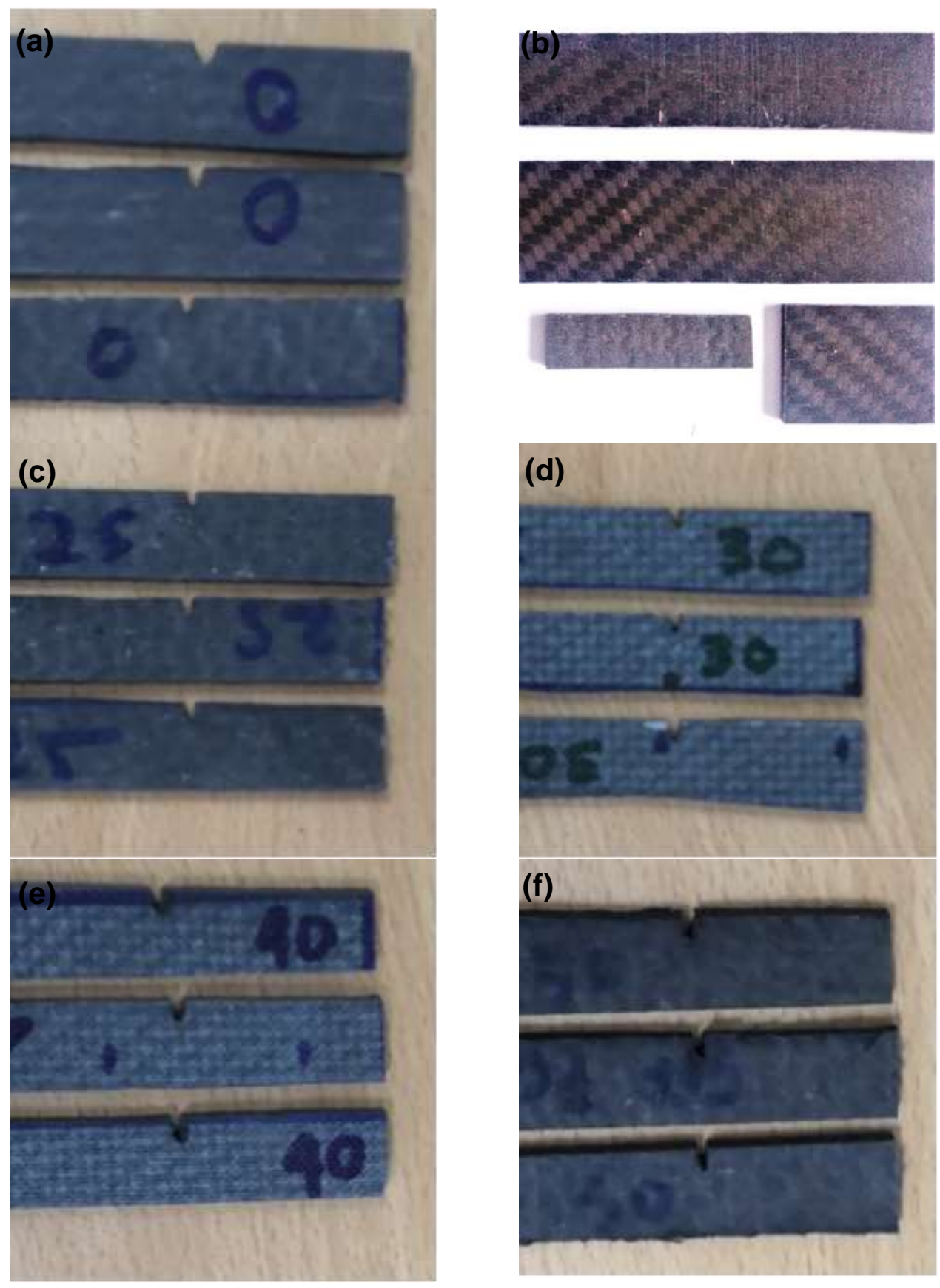

Fig. 20. Appearance of laminated fiber carbon composite with various weight percentages of jatropha bio-epoxy: (a) 0\% jatropha bio-epoxy, (b) 18\% jatropha bio-epoxy, (c) 25\% jatropha bioepoxy, (d) 30\% jatropha bio-epoxy, (e) 40\% jatropha bio-epoxy, and (f) 50\% jatropha bio-epoxy

In Fig. 21(c), laminated composites of the same bio-epoxy are compared to different reinforcements of 10 layers of fiber carbon and 10 layers of fiber glass. The fiber glass laminated composite had $12 \%$ higher density compared to fiber carbon. Furthermore, the trend was comparable between $0 \mathrm{wt} \%, 25 \mathrm{wt} \%$, and $50 \mathrm{wt} \%$ of bio-epoxy for both reinforcements. The increment in theoretical density was because vegetable oil contained fatty acids that had large molecular chains compared to petrochemical-based epoxy, and the length of molecular chain contributed to the weight of cured epoxy (Bruckner 2002). However, the experimental density began to decrease as bio-epoxy surpassed $30 \mathrm{wt} \%$ and 
increased up to $50 \mathrm{wt} \%$. The probable cause of this decrement trend was the void content inside the laminated composites, because all parameters and setup during fabrication process were the same.

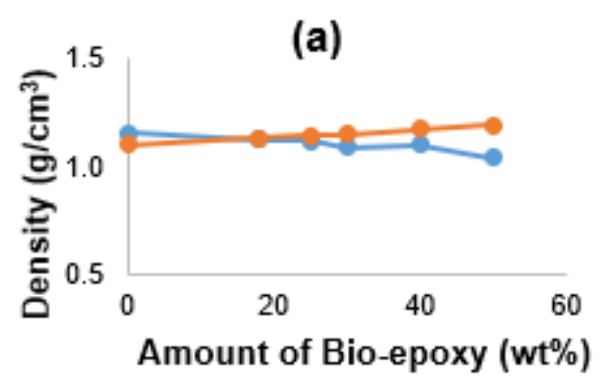

$\longrightarrow$ Pure Resin $\multimap$ Theoretical density
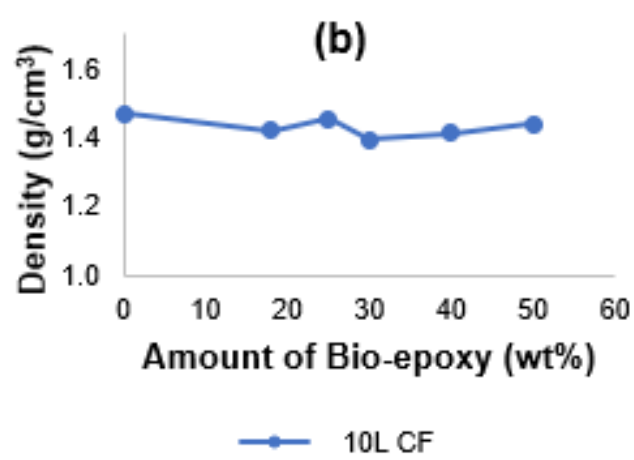

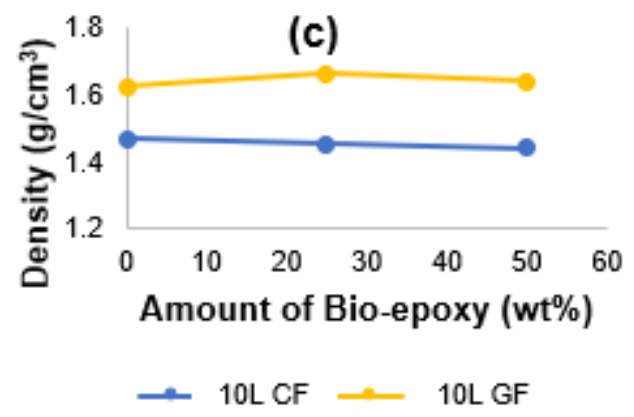

Fig. 21. Density of bio-epoxy and laminated composites

Figure 22(a) demonstrates the thickness of laminated composites with bio-epoxy of $0 \mathrm{wt} \%, 18 \mathrm{wt} \%, 25 \mathrm{wt} \%, 30 \mathrm{wt} \%, 40 \mathrm{wt} \%$, and $50 \mathrm{wt} \%$ with 10 layers of fiber carbon reinforcement. All thickness was greater than $2.1 \mathrm{~mm}$ and comparable between $0 \mathrm{wt} \%, 18$ $\mathrm{wt} \%$, and $25 \mathrm{wt} \%$ of bio-epoxy. However, thickness increased as much as $33 \%$ as bioepoxy surpassed $30 \mathrm{wt} \%$. The thickness decreased for $40 \mathrm{wt} \%$ and $50 \mathrm{wt} \%$. Figure 22(b) shows the comparison between laminated composites of bio-epoxy at $0 \mathrm{wt} \%, 25 \mathrm{wt} \%$, and $50 \mathrm{wt} \%$ with 10 layers of fiber carbon and 10 layers of fiber glass. Both reinforcements decreased slightly as the bio-epoxy increased, but bio-epoxy of $25 \mathrm{wt} \%$ proved to be a suitable candidate for replacing $0 \mathrm{wt} \%$. Even though the density of laminated composite with bio-epoxy of $30 \mathrm{wt} \%$ showed low value, its thickness was higher than $25 \mathrm{wt} \%$. The only reason for this was the high void content inside laminated composite. High void content made the composite lighter as the amount of trapped air bubble was also high. The trapped air bubbles between laminated layers increased the total thickness. This occurred when $30 \mathrm{wt} \%, 40 \mathrm{wt} \%$, and $50 \mathrm{wt} \%$ of bio-epoxy were used as matrix in fiber carbon. As for fiber glass, thickness was slightly lower for $25 \mathrm{wt} \%$ and $50 \mathrm{wt} \%$, but density was also slightly higher. The high permeability in fiber glass made thickness lower compared to fiber carbon laminated composite. In addition, fatty acids in bio-epoxy are known to be bulky and flexible, thus slightly increasing the volume or thickness of cured bio-epoxy (Liu et al. 2015). 
(a)

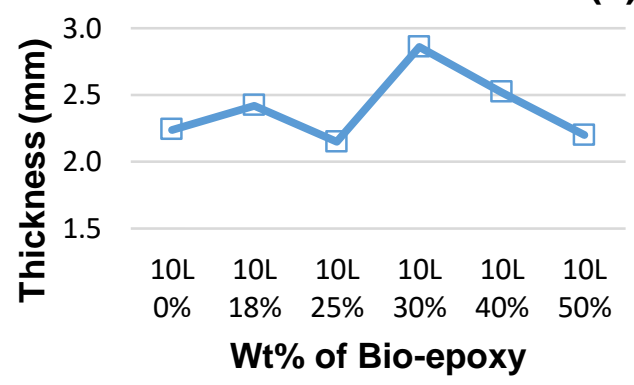

$\square$ Laminated CF (b)

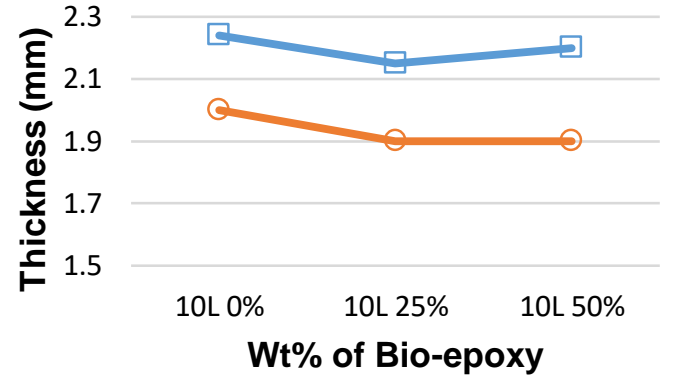

$\because$ Laminated CF $\cong$ Laminated GF

Fig. 22. Thickness of laminated composites with various bio-epoxy and various reinforcements

Figure 23 reveals the moisture content of specimens with bio-epoxy from $0 \mathrm{wt} \%$ to $50 \mathrm{wt} \%$. All specimens had increment trends of moisture absorption from day 0 . The increment trend continued until several days before a saturation point where there was a balance of moisture loss/absorption. As expected, $0 \mathrm{wt} \%$ bio-epoxy had the lowest total moisture content, which was $0.15 \%$, and $30 \mathrm{wt} \%$ bio-epoxy had the highest at $0.29 \%$. As for other specimens, such as $25 \mathrm{wt} \%, 40 \mathrm{wt} \%$, and $50 \mathrm{wt} \%$, their moisture content was $0.17 \%, 0.18 \%$, and $0.21 \%$, respectively, on day 21 . Synthetic epoxy absorbed moisture up to day 7 before saturation, with days 10,12, 14, and 15 for $25 \mathrm{wt} \%, 30 \mathrm{wt} \%$, $40 \mathrm{wt} \%$, and $50 \mathrm{wt} \%$ bio-epoxy, respectively.

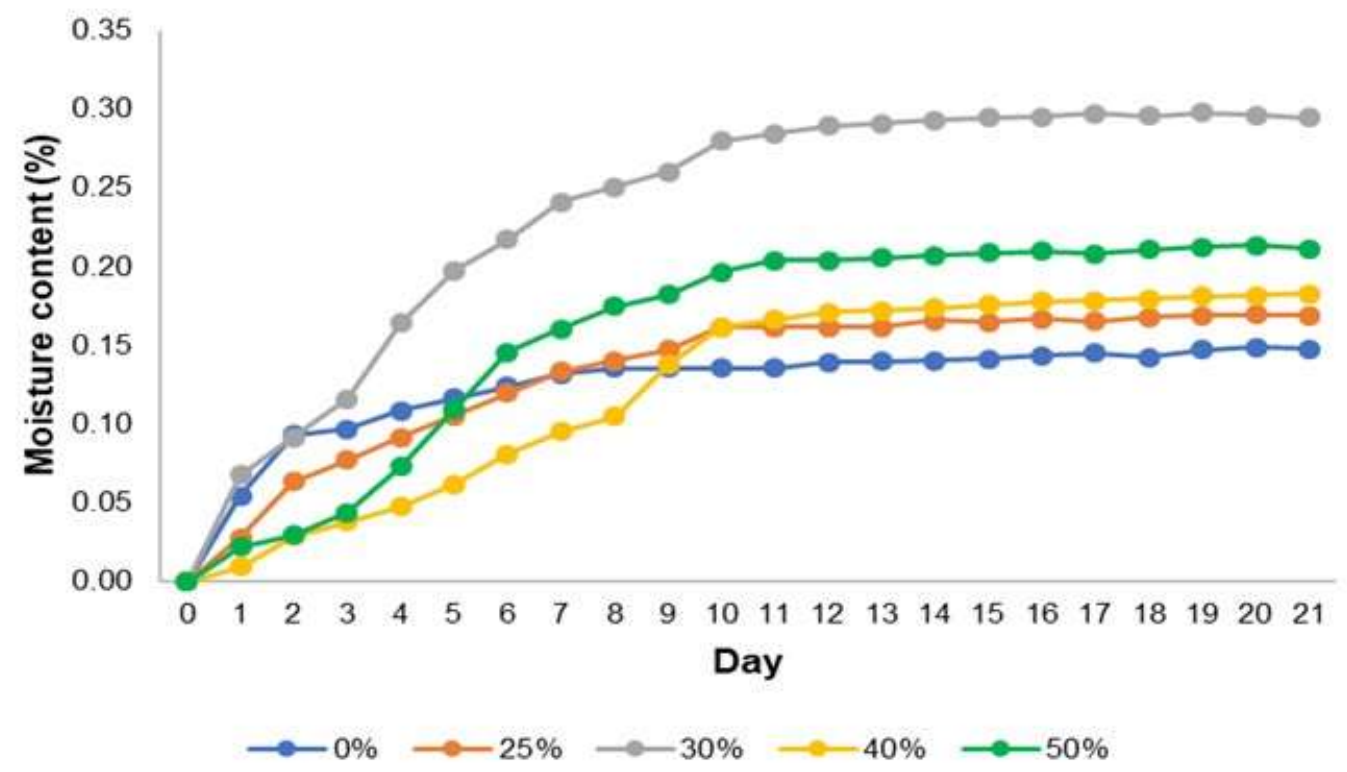

Fig. 23. Moisture content by weight $\%$ of bio-epoxy

As the amount of wt\% bio-epoxy increased, moisture absorption increased with a greater time for moisture absorption saturation. This was most likely due to higher void content inside matrices with bio-epoxy due to inevitable gasification phenomenon during the fabrication process. This became worse as water moisture content inside a matrix 
increased. This was because water acted as plasticizer, which sabotaged the interfacial bond between fiber and matrix and thus weakened the composite and modified its characteristics from the estimated values (Cuinat-Guerraz et al. 2016). Thus, obtaining the lowest content of water moisture was important. Similar results for epoxy were obtained by Pérez-Pacheco et al. (2013) with a three-model proposal driving to the moisture absorption: (1) bulk dissolution of water in the polymer network; (2) moisture absorption onto the surface of holes that defined the excess free volume of the glassy structure; and (3) hydrogen bonding between hydrophilic group of polymer and water, that is responsible for the decrement of $\tan \delta$ value.

Fiber volume fraction is important for quantifying the quality of laminated composites that directly affect mechanical performances later as well as verifying its fabrication process. As the fiber volume fraction in a composite laminate increased, its mechanical performances increased. Figure 24 indicates the experimental fiber volume fraction between laminated fiber carbon and fiber glass composites and their theoretical values. Figure 24 shows that fiber volume fraction varied from $41 \%$ to $53 \%$ and $51 \%$ to $53 \%$ for fiber carbon and fiber glass, respectively. It was perfectly normal to obtain a lower value than the theoretical fiber volume fraction that was calculated via rule of mixtures. Despite the gap between theoretical value and experimental value of fiber volume fraction and the reduction trend, by achieving more than $40 \%$ of fiber volume fraction, the values were considered acceptable because of different types of woven resin would differ in their volume (Tan et al. 2014; Wong et al. 2014). Subbiah (2016) made a conclusion from his experiments that vacuum infusion is a promising technique for fabricating bio-based composite with superior mechanical properties compared to the hand lay-up process. The micrograph showed fewer voids and moisture absorption along with tensile results that revealed improved interfacial bonding between fiber and matrix (Subbiah 2016). According to Strong (2008), when the laminated composite has 50\% fiber volume fraction, the penetration is extensive and rapid, but to achieve more than that, penetration must be less intensive and less rapid. This was related to permeability of fibers and to other parameters, such as resin viscosity, pressure, and temperature during infusion, etc. 


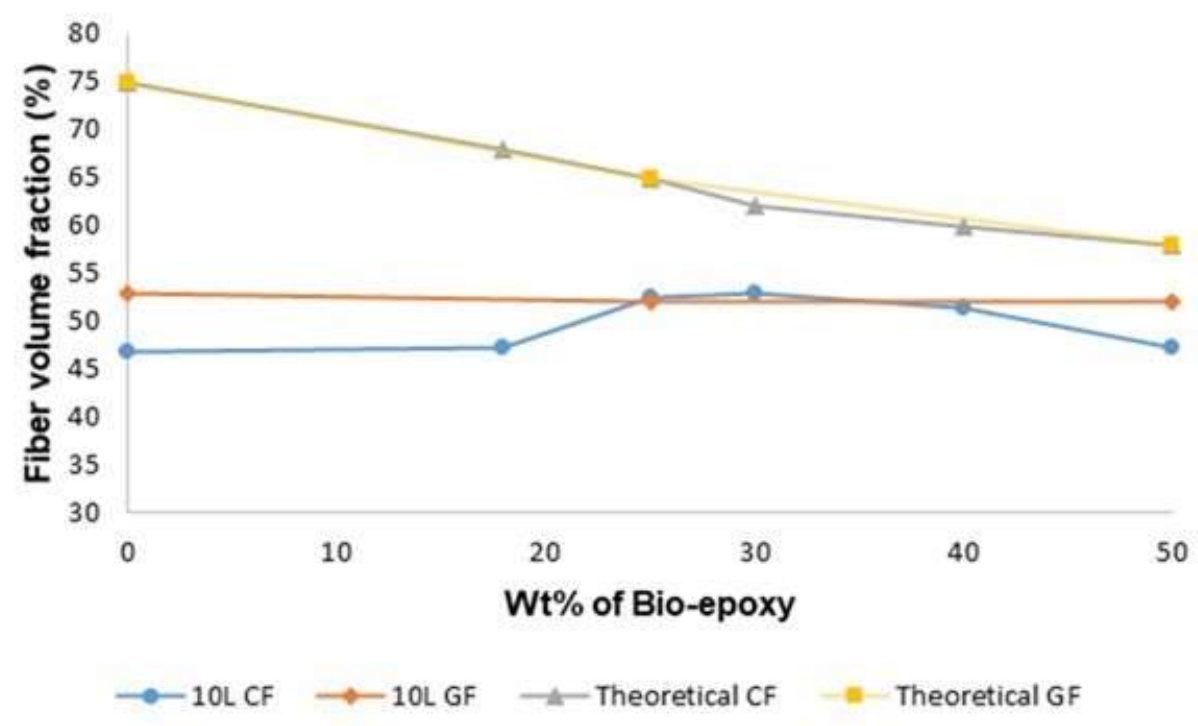

Fig. 24. Fiber volume fraction of fiber carbon and fiber glass laminated composites with different bio-epoxy amounts

\section{Flammability Properties}

Flammability properties could be observed easily by using UL94 HB (Horizontal Burning) test standard, as the experiments are able to describe the flammability phenomenon which produce smoke, droplets, and ability to self-extinguished in a certain duration. In Fig. 25, two types of specimens of fiber carbon and fiber glass with varied wt $\%$ of bio-epoxy were set up for the horizontal burning test. For laminated fiber glass, self-extinguishing time increased as bio-epoxy increased. When $25 \mathrm{wt} \%$ and $50 \mathrm{wt} \%$ bioepoxy were added, self-extinguishing time increased $32 \%$ and $68 \%$, respectively, compared to fully synthetic epoxy. For laminated fiber carbon, self-extinguishing time also increased as bio-epoxy increased compared to synthetic epoxy. However, the time was more than double, which was $114 \%$ more when $18 \mathrm{wt} \%$ bio-epoxy was added. When 25 wt $\%$ bio-epoxy was added, the time increased $181 \%$ compared to fully synthetic epoxy. The increment continued even after more than $30 \mathrm{wt} \%$ bio-epoxy was in the composite. Normally, most bio-based composites are less fire-resistant compared to synthetic ones. As expected, the horizontal flammability test showed that bio-epoxy had lower fire resistance. The time for flame on laminated fiber carbon to self-extinguish increased as the amount of bio-epoxy increased. The same phenomenon also occurred for laminated fiber glass. Even though bio-epoxy increased the amount of aromatic groups in the FTIR graph and cured with amine hardener, it could not handle flame better than synthetic epoxy, most likely due to high temperatures up to $1200{ }^{\circ} \mathrm{C}$ (Paluvai et al. 2014; Tengye 2017). In addition, no dripping occurred during the fire, and flame propagation was slow and on par for both bioepoxy and epoxy. 


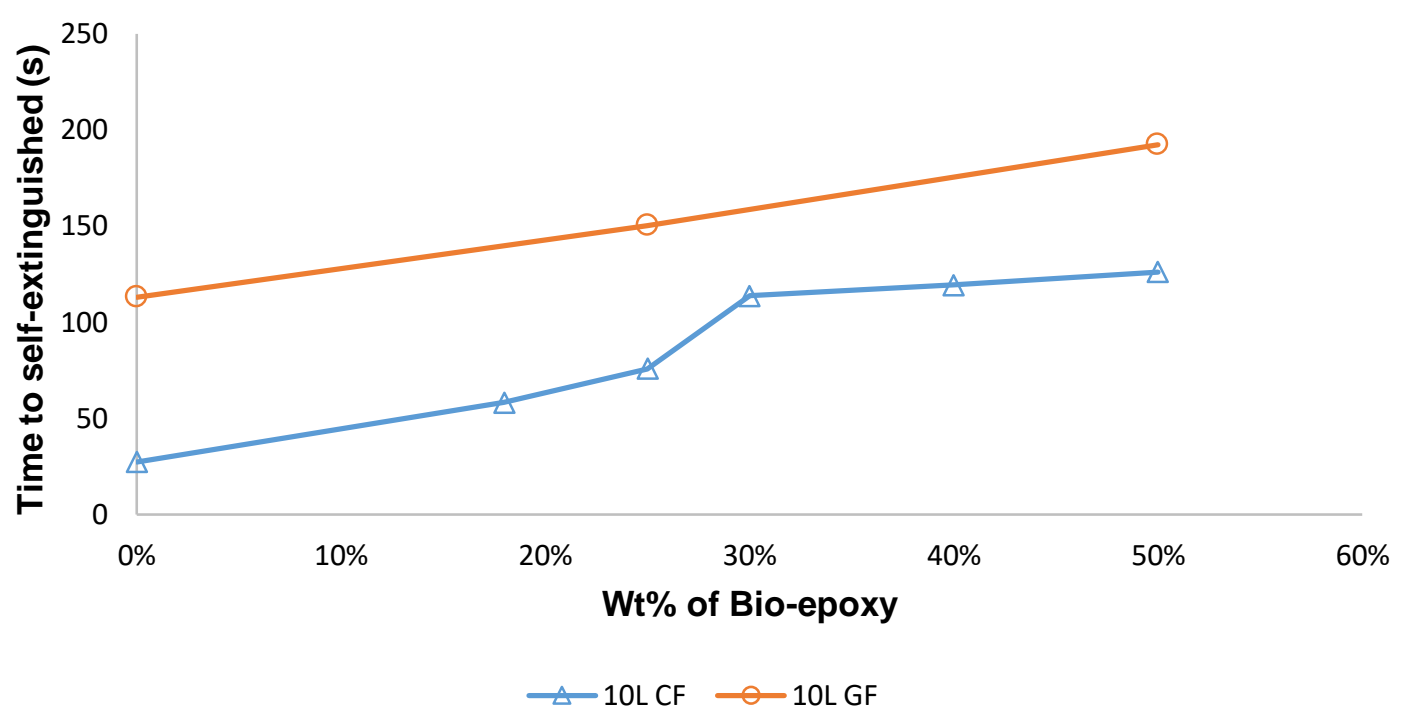

Fig. 25. Horizontal burning with time to self-extinguish with increment of wt\% of bio-epoxy

\section{Biodegradation}

A soil burial test was conducted in a soil-enriched environment to determine direct biodegradability of jatropha bio-epoxy. Figure 26 shows an accumulated and separate weight loss within 30 days (d) and $100 \mathrm{~d}$ of burying. This showed that fully synthetic epoxy had approximately $0 \%$ weight loss for $30 \mathrm{~d}$, and even $100 \mathrm{~d}$. The negative weight loss occurred due to a slight amount of dirt that could not be removed. A weight loss up of $0.13 \%$ and $0.09 \%$ for $30 \mathrm{~d}$ and $100 \mathrm{~d}$, respectively, began when jatropha bio-epoxy was introduced in proportions as small as $18 \mathrm{wt} \%$. When jatropha bio-epoxy was increased to $25 \mathrm{wt} \%$, the weight loss (\%) increased to $0.36 \%$ and $0.39 \%$ for $30 \mathrm{~d}$ and $100 \mathrm{~d}$, respectively. The trend of weight loss continued to increase up to $2.1 \%$ for $30 \mathrm{~d}$ and $1.1 \%$ for $100 \mathrm{~d}$, respectively, with the maximum $50 \mathrm{wt} \%$ amount of jatropha bio-epoxy. The histogram in Fig. 26 also displays accumulated weight loss for each specimen with increasing amounts of jatropha bio-epoxy. The weight loss started small for $18 \mathrm{wt} \%$ jatropha bio-epoxy, then was remarkably amplified by approximately two times for $25 \mathrm{wt} \%$ and $30 \mathrm{wt} \%$. Next, the weight loss continuously increased two-fold for $40 \mathrm{wt} \%$ and $50 \mathrm{wt} \%$.

The duration of days buried in soil played an important role in the biodegradation process, which was shown by the increase in weight loss when duration increased. Initially, weight loss was quite low, and this might have been due to biodegradation that had not yet begun. Once the process of biodegradation began, the weight loss rate became more noteworthy. The results showed that jatropha bio-epoxy had enhanced the biodegradation process tremendously. This result could be assigned to the degradation progression either by microorganism activity or material deterioration such as cracking, breakage, and fragmentation. This finding might have been attributed to lipases that promoted higher oxygenation to hydrophobic substances, such as epoxy/jatropha bio-epoxy itself. The polymer chain would shorten and then facilitate the deterioration process over time. Thus, introducing jatropha bio-epoxy enabled the non-biodegradable matrix to decompose, starting with attracting the oxygenation process through lipases, followed by shortening polymer chains with microorganism activities on the surface. 
Figure 27 shows the surface condition of specimens after 100 days of soil burial test of specimens with $0 \mathrm{wt} \%, 18 \mathrm{wt} \%, 25 \mathrm{wt} \%, 30 \mathrm{wt} \%, 40 \mathrm{wt} \%$, and $50 \mathrm{wt} \%$ jatropha bio-epoxy. These images were taken under an optical microscope with five times magnification to prove that surface degradation of specimens occurred with improvement of degradation by increasing jatropha bio-epoxy up to $50 \mathrm{wt} \%$. The micro-sized holes with spherical shape were suspected to be evidence of biodegradation due to microorganism activity similar to those in images by Kadam et al. (2015) and Ikada (1999).

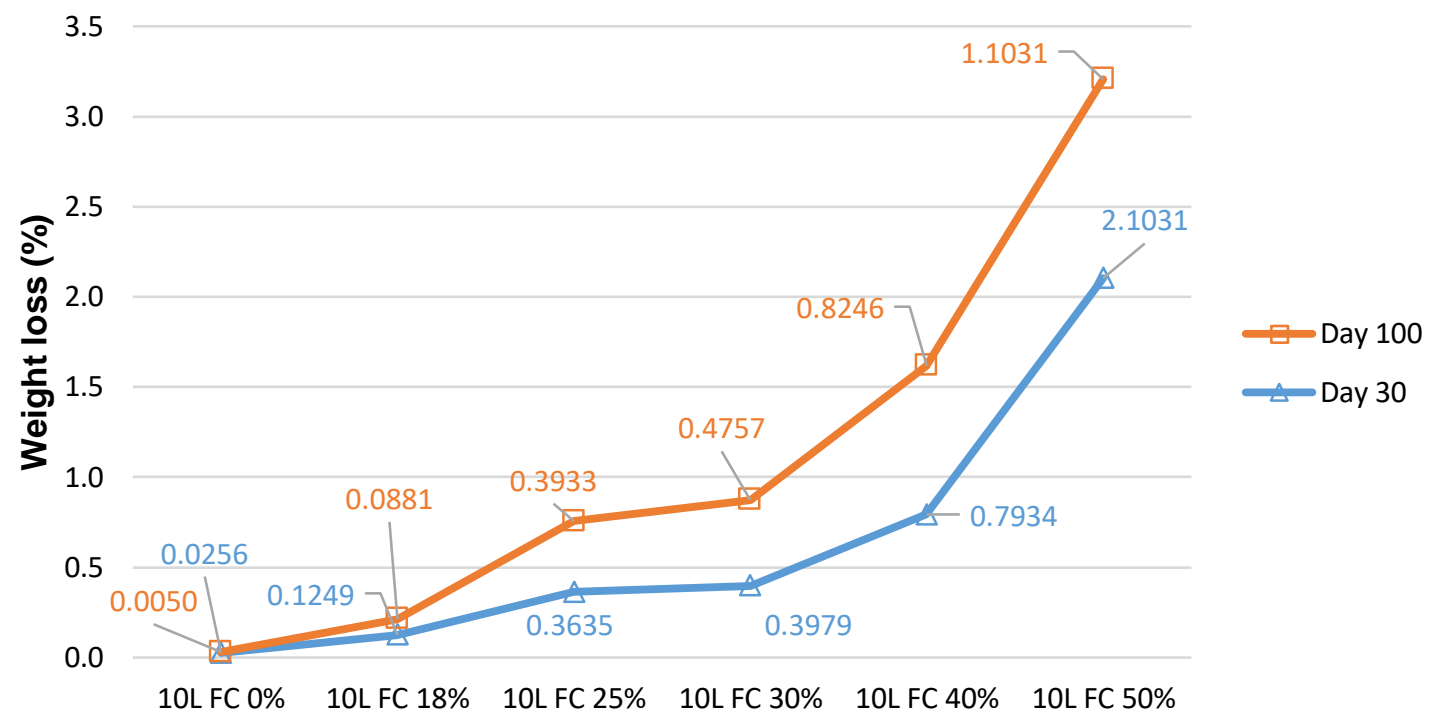

Fig. 26. Weight loss of specimen with variation of wt\% bio-epoxy in soil burial test
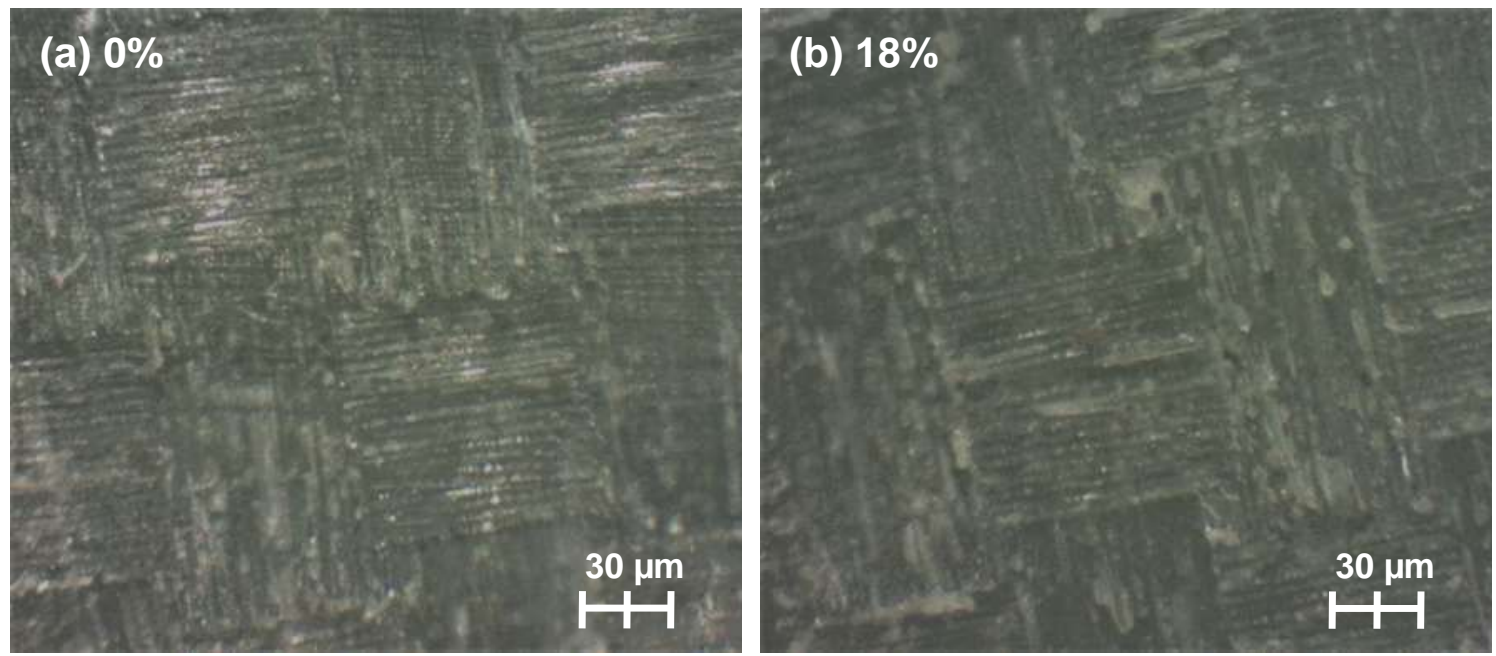


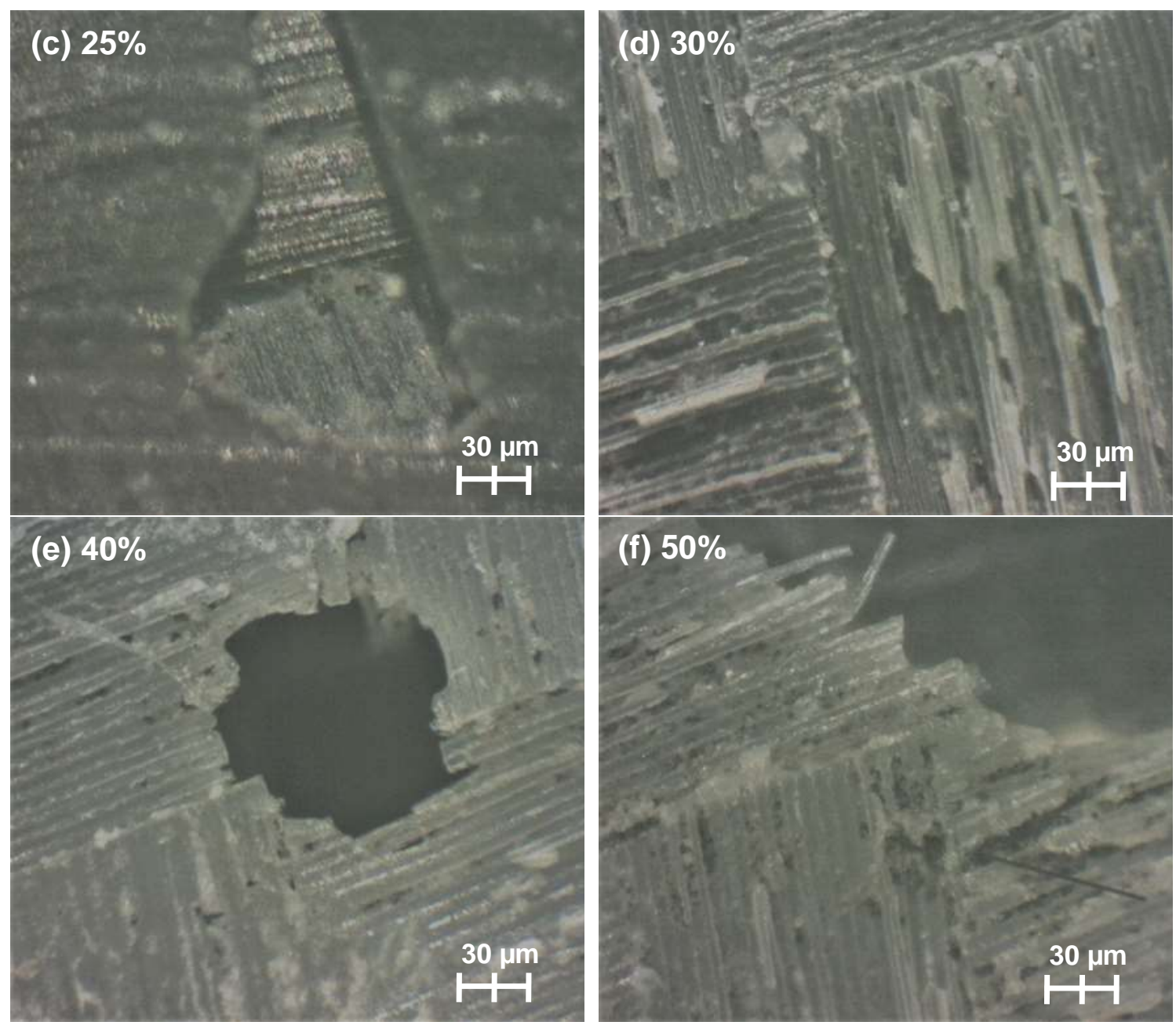

Fig. 27. Traces of biodegradation process due to possible microorganism activity on the surface of laminated composites in different wt\% of jatropha bio-epoxy 


\section{CONCLUSIONS}

1. The Fourier transform infrared (FTIR) analysis showed that blending bio-epoxy/epoxy improved the $-\mathrm{OH}$ bonding, which led to improved intermolecular bonding with the reinforcement. However, more - $\mathrm{OH}$ bonding formed when the amount of bio-epoxy increased, which led to higher hydrophilic character. The curing process of blended bio-epoxy/epoxy almost fully crosslinked the molecules, despite the fact that higher amounts of bio-epoxy left more considerable amounts of non-crosslinked molecules. The fingerprints region of the blended bio-epoxy/epoxy remained the same as the epoxy group.

2. Mechanical performances from flexural and tensile tests mostly decreased when the bio-epoxy amount was increased. Micrograph images from ruptured tensile test revealed a strong interfacial bonding between carbon fibers and blended bioepoxy/epoxy matrix at below $25 \% \mathrm{wt} \%$. In contrast, absorbed impact energy was improved with increasing bio-epoxy amount.

3. Thermal behaviour analysis was in agreement, which revealed that the glass transition temperature $T_{\mathrm{g}}$ was reduced when the amount of bio-epoxy increased. The thermogravimetric analysis (TGA) curvatures showed high thermal stability at the range of $280{ }^{\circ} \mathrm{C}$ to $450{ }^{\circ} \mathrm{C}$ when added with bio-epoxy. Higher amounts of bio-epoxy led to lowered total thermal stability and low char. The dynamic mechanical analysis (DMA) results showed a high miscibility of bio-epoxy/epoxy as they exhibited one peak in each curvature. However, adding more bio-epoxy led to decreased $T_{\mathrm{g}}$, storage modulus, loss modulus, and damping ability as the temperature increased. The blended bio-epoxy/epoxy became viscous faster as the bio-epoxy amount increased.

4. Physical characteristics of blended bio-epoxy/epoxy differed in certain aspects. The color of the blended matrix changed from totally transparent into a certain percentage of translucency that was not totally transparent. Density of blended bio-epoxy/epoxy decreased as the amount of bio-epoxy increased. Thickness and swelling events by adding bio-epoxy were not affected much, but it was evident that adding high amounts of bio-epoxy caused a gasification phenomenon during the vacuum infusion process.

5. Moisture content of blended bio-epoxy/epoxy slightly increased and took much more time to saturate when a higher amount of bio-epoxy was added.

6. The ability to self-extinguish the burning compound of bio-epoxy/epoxy decreased, so it took more time to self-extinguish. There was no spill-off during burning when bioepoxy was added.

7. Blending bio-epoxy/epoxy improved the biodegradability of the substance. A higher amount of bio-epoxy led to better biodegradation when buried in the soil. Overall, these tests revealed that incorporation of bio-epoxy at an amount not exceeding $25 \mathrm{wt} \%$ into the matrix of laminated composites showed comparable performances with fully synthetic specimens. Furthermore, $30 \mathrm{wt} \%$ bio-epoxy also showed good performance, but too many voids occurred inside the composites. Thus, $25 \mathrm{wt} \%$ bio-epoxy was selected as an optimal ratio of blending with synthetic epoxy to promote the usage of renewable matrix and replace existing non-renewable epoxy. 


\section{ACKNOWLEDGEMENTS}

The authors are grateful to the Ministry of Higher Education of Malaysia for their financial support. This research was initiated by a collaboration between the Universiti Putra Malaysia (UPM) and the Aerospace Malaysian Innovative Centre (AMIC) (Grant No. 6300801).

\section{REFERENCES CITED}

Ariza-Montobbio, P., and Lele, S. (2010). "Jatropha plantations for biodiesel in Tamil Nadu, India: Viability, livelihood trade-offs, and latent conflict," Ecological Economics 70(2), 189-195. DOI: 10.1016/j.ecolecon.2010.05.011

Aung, M. M., Yaakob, Z., Kamarudin, S., and Abdullah, L. C. (2014). "Synthesis and characterization of Jatropha (Jatropha curcas L.) oil-based polyurethane wood adhesive," Ind. Crop. Prod. 60, 177-185. DOI: 10.1016/j.indcrop.2014.05.038

ASTM D790-17 (2017). "Standard test methods for flexural properties of unreinforced and reinforced plastics and electrical insulating materials," ASTM International, West Conshohocken, PA, USA.

ASTM D3039/D3039M-17 (2017). "Standard test method for tensile properties of polymer matrix composite materials," ASTM International, West Conshohocken, PA, USA.

ASTM D3171-15 (2015). "Standard test methods for constituent content of composite materials," ASTM International, West Conshohocken, PA, USA.

ASTM D3418-15 (2015). "Standard test method for transition temperatures and enthalpies of fusion and crystallization of polymers by differential scanning calorimetry," ASTM International, West Conshohocken, PA, USA.

ASTM D4065-12 (2012). "Standard practice for plastics: Dynamic mechanical properties: Determination and report of procedures," ASTM International, West Conshohocken, PA, USA.

ASTM D6110-18 (2018). "Standard test method for determining the Charpy impact resistance of notched specimens of plastics," ASTM International, West Conshohocken, PA, USA.

ASTM E1131-08 (2014). "Standard test method for compositional analysis by thermogravimetry," ASTM International, West Conshohocken, PA, USA.

Barbosa, A. D. P., Oliveira, M. P., Altoé, G. R., Margem, F. M., and Monteiro, S. N. (2014). "Charpy impact test of epoxy matrix composites reinforced with buriti fibers," Mater. Sci. Forum 775-776, 296-301. DOI:

10.4028/www.scientific.net/msf.775-776.296

Bibiao, J., Jianjun, H., Wenyun, W., Luxia, J., and Xinxian, C. (2001). "Synthesis and properties of novel polybismaleimide oligomers," Eur. Polym. J. 37(3), 463-470. DOI: $10.1016 / \mathrm{S} 0014-3057(00) 00147-6$

Boll, D. J., Bascom, W. D., and Motiee, B. (1985). "Moisture absorption by structural epoxy-matrix carbon-fiber composites," Compos. Sci. Technol. 24(4), 253-273. DOI: 10.1016/0266-3538(85)90025-9

Bruckner, R. (2002). Advanced Organic Chemistry, Academic Press, Cambridge, MA, USA. DOI: 10.1016/B978-0-12-138110-3.X5000-4

Chauhan, P. S., and Chibber, V. K. (2013). "Epoxidation in karanja oil for biolubricant 
applications," Int. J. Pharm. Biol. Sci. Arch. 1(1), 61-70.

Chiu, Y.-C., Chou, I.-C., Tseng, W.-C., and Ma, C.-C. M. (2008). "Preparation and thermal properties of diglycidylether sulfone epoxy," Polym. Degrad. Stabil. 93(3), 668-676. DOI: 10.1016/j.polymdegradstab.2007.12.014

Cuinat-Guerraz, N., Dumont, M. J., and Hubert, P. (2016). "Environmental resistance of flax/bio-based epoxy and flax/polyurethane composites manufactured by resin transfer moulding," Compos. Part A-Appl. S. 88, 140-147. DOI: 10.1016/j.compositesa.2016.05.018

Deng, J., Liu, X., Li, C., Jiang, Y., and Zhu, J. (2015). "Synthesis and properties of a biobased epoxy resin from 2,5-furandicarboxylic acid (FDCA)," RSC Adv. 5(21), 1593015939. DOI: $10.1039 / \mathrm{c} 5 \mathrm{ra00242g}$

Dharma, S., Masjuki, H. H., Ong, H. C., Sebayang, A. H., Silitonga, A. S., Kusumo, F., and Mahlia, T. M. I. (2016). "Optimization of biodiesel production process for mixed Jatropha curcas - Ceiba pentandra biodiesel using response surface methodology," Energy Convers. Manage. 115, 178-190. DOI: 10.1016/j.enconman.2016.02.034

Ezzah, F. (2016). Production Characterization and Kinetic Modelling of Malaysia Jatropha Oil Based Bio-Epoxy Resins, Master's Thesis, Universiti Putra Malaysia, Serdang, Malaysia.

Gibbins, M. N., and Hoffman, D. J. (1982). Environmental Exposure Effects on Composite Materials for Commercial Aircraft (Report No. 3502), National Aeronautics and Space Administration, Washington, D.C., USA.

Gogoi, P., Boruah, M., Sharma, S., and Dolui, S. K. (2015). "Blends of epoxidized alkyd resins based on jatropha oil and the epoxidized oil cured with aqueous citric acid solution: A green technology approach," ACS Sustain. Chem. Eng. 3(2), 261-268. DOI: $10.1021 / \mathrm{sc} 500627 \mathrm{u}$

Gogoi, P., Boruah, M., Bora, C., and Dolui, S. K. (2014). "Jatropha curcas oil based alkyd/epoxy resin/expanded graphite (EG) reinforced bio-composite: Evaluation of the thermal, mechanical and flame retardancy properties," Progress in Organic Coatings, 77(1), 87-93. DOI: 10.1016/j.porgcoat.2013.08.006

Groover, M. P. (2010). Fundamentals of Modern Manufacturing, Fourth Edition, John Wiley \& Sons, New York, NY, USA.

Hafiezal, M., Khalina, A., Zurina, Z., Azaman, M., and Hanafee, Z. (2019). "Thermal and flammability characteristics of blended jatropha bio-epoxy as matrix in carbon fiberreinforced polymer," J. Compos. Sci. 3(1), Article Number 6. DOI:

$10.3390 / j \operatorname{cs} 3010006$

Hafiezal, M. R. M., Abdan, K., Azaman, M. D., Abidin, Z. Z., and Hanafee, Z. M. (2017). "Initial study of new bio-based epoxy in carbon fiber reinforced composite panel manufactured by vacuum assisted resin transfer moulding," AIP Conf. Proc. 1885(1), Article ID 020066. DOI: 10.1063/1.5002260

Hafiezal, M. R. M., Khalina, A., Zurina, Z. A., Azaman, M. D., and Hanafee, Z. M. (2018). "Physical characterization of carbon fiber reinforced composite with blended epoxidized jatropha oil (EJO) resin," IOP Conf. Ser.: Mater. Sci. Eng. 368(1), Article ID 012003. DOI: 10.1088/1757-899X/368/1/012003

Hazmi, A. S. A., Aung, M. M., Abdullah, L. C., Salleh, M. Z., and Mahmood, M. H. (2013). "Producing Jatropha oil-based polyol via epoxidation and ring opening," Ind. Crop. Prod. 50, 563-567. DOI: 10.1016/j.indcrop.2013.08.003

Ikada, E. (1999). "Electron microscope observation of biodegradation of polymers," $J$. Environ. Polym. Degrad. 7(4), 197-201. DOI: 10.1023/A:1022882732403 
Ishak, A. A., and Salimon, J. (2013). "Synthesis of rubber seed oil and trimethylolpropane based biolubricant base stocks," Malays. J. Anal. Sci. 17(3), 414421.

Jumaidin, R., Sapuan, S. M., Jawaid, M., Ishak, M. R., and Sahari, J. (2017). "Effect of seaweed on mechanical, thermal, and biodegradation properties of thermoplastic sugar palm starch/agar composites," Int. J. Biol. Macromol. 99, 265-273. DOI: 10.1016/j.ijbiomac.2017.02.092

Kadam, A., Pawar, M., Yemul, O., Thamke, V., and Kodam, K. (2015). "Biodegradable biobased epoxy resin from karanja oil," Polymer 72, 82-92. DOI: 10.1016/j.polymer.2015.07.002

Kalam, M. A., Ahamed, J. U., and Masjuki, H. H. (2012). "Land availability of Jatropha production in Malaysia," Renewable and Sustainable Energy Reviews 16(6), 39994007. DOI: 10.1016/j.rser.2012.03.025

Kuo, P.-Y., Barros, L. D. A., Sheen, Y.-C., Sain, M., Tjong, J. S. Y., and Yan, N. (2016). "Thermal degradation of extractive-based bio-epoxy monomer and network: Kinetics and mechanism," J. Anal. Appl. Pyrol. 117, 199-213. DOI:

10.1016/j.jaap.2015.11.014

Kuo, P.-Y., Sain, M., and Yan, N. (2014). "Synthesis and characterization of an extractive-based bio-epoxy resin from beetle infested Pinus contorta bark," Green Chem. 16(7), 3483-3493. DOI: 10.1039/c4gc00459k

La Rosa, A. D., Recca, G., Summerscales, J., Latteri, A., Cozzo, G., and Cicala, G. (2014). "Bio-based versus traditional polymer composites. A life cycle assessment perspective," J. Clean. Prod. 74, 135-144. DOI: 10.1016/j.jclepro.2014.03.017

Lagel, M. C., Hai, L., Pizzi, A., Basso, M. C., Delmotte, L., Abdalla, S., Zahed, A., and Al-Marzouki, F. M. (2016). "Automotive brake pads made with a bioresin matrix," Ind. Crop. Prod. 85, 372-381. DOI: 10.1016/j.indcrop.2015.12.090

Li, L., Yao, X., Li, H., Liu, Z., Ma, W., and Liang, X. (2014). "Thermal stability of oxygen-containing functional groups on activated carbon surfaces in a thermal oxidative environment," J. Chem. Eng. Jpn. 47(1), 21-27. DOI: 10.1252/jcej.13we193

Liu, K., Madbouly, S. A., and Kessler, M. R. (2015). "Biorenewable thermosetting copolymer based on soybean oil and eugenol," Eur. Polym. J. 69, 16-28. DOI: 10.1016/j.eurpolymj.2015.05.021

Manthey, N. W., Cardona, F., and Aravinthan, T. (2012). "Cure kinetic study of epoxidized hemp oil cured with a multiple catalytic system," J. Appl. Polym. Sci. 125(52), E511-E517. DOI: 10.1002/app.35561

Mincheva, R., Delangre, A., Raquez, J.-M., Narayan, R., and Dubois, P. (2013). "Biobased polyesters with composition-dependent thermomechanical properties: Synthesis and characterization of poly(butylene succinate-co-butylene azelate)," Biomacromolecules 14(3), 890-899. DOI: 10.1021/bm301965h

Morales, A. P., Güemes, A., Fernandez-Lopez, A., Valero, V. C., and Llano, S. D. L. R. (2017). "Bamboo - polylactic acid (PLA) composite material for structural applications," Materials 10(11), 1286. DOI: 10.3390/ma10111286

National Aeronautics and Space Administration (NASA) (1975). Reflective Superinsulation Materials, Midwest Research Institute, Kansas City, MO, USA.

Ooi, T. L., and Yeong, S. K. (2000). "Studies on factor affecting the colour stability of some commercial palm fatty acids," Journal of Oil Palm Research 12(2), 63-72.

Paluvai, N. R., Mohanty, S., and Nayak, S. K. (2014). "Synthesis and modifications of epoxy resins and their composites: A review," Polym.-Plast. Technol. Eng. 53(16), 
1723-1758. DOI: 10.1080/03602559.2014.919658

Pan, X., Sengupta, P., and Webster, D. C. (2011). "High biobased content epoxyanhydride thermosets from epoxidized sucrose esters of fatty acids," Biomacromolecules 12(6), 2416-2428. DOI: 10.1021/bm200549c

Paramarta, A., and Webster, D. C. (2016). "Bio-based high performance epoxy-anhydride thermosets for structural composites: The effect of composition variables," React. Funct. Polym. 105, 140-149. DOI: 10.1016/j.reactfunctpolym.2016.06.008

Pawar, M., Kadam, A., Yemul, O., Thamke, V., and Kodam, K. (2016). "Biodegradable bioepoxy resins based on epoxidized natural oil (cottonseed \& algae) cured with citric and tartaric acids through solution polymerization: A renewable approach," Ind. Crop. Prod. 89, 434-447. DOI: 10.1016/j.indcrop.2016.05.025

Pérez-Pacheco, E., Cauich-Cupul, J. I., Valadez-González, A., and Herrera-Franco, P. J. (2013). "Effect of moisture absorption on the mechanical behavior of carbon fiber/epoxy matrix composites," J. Mater. Sci. 48(5), 1873-1882. DOI: 10.1007/s 10853-012-6947-4

Roudsari, G. M., Mohanty, A. K., and Misra, M. (2014). "Study of the curing kinetics of epoxy resins with biobased hardener and epoxidized soybean oil," ACS Sustain. Chem. Eng. 2(9), 2111-2116. DOI: 10.1021/sc500176z

Rwawiire, S., Tomkova, B., Militky, J., Jabbar, A., and Kale, B. M. (2015).

"Development of a biocomposite based on green epoxy polymer and natural cellulose fabric (bark cloth) for automotive instrument panel applications," Compos. Part BEng. 81, 149-157. DOI: 10.1016/j.compositesb.2015.06.021

Saba, N., Jawaid, M., Alothman, O. Y., and Paridah, M. T. (2016). "A review on dynamic mechanical properties of natural fibre reinforced polymer composites," Constr. Build. Mater. 106, 149-159. DOI: 10.1016/j.conbuildmat.2015.12.075

Sammaiah, A., Padmaja, K. V., Badari, R., and Prasad, N. (2014). "Synthesis of epoxy jatropha oil and its evaluation for lubricant properties," Journal of Eleo Science 643(6), 637-643. DOI: 10.5650/jos.ess13172

Satheesh Kumar, M. N., Yaakob, Z., Mohan, N., Siddaramaiah, and Babu, S. P. (2010). "Mechanical and abrasive wear studies on biobased jatropha oil cake incorporated glass-epoxy composites," J. Am. Oil Chem. Soc. 87(8), 929-936. DOI: 10.1007/s11746-010-1575-0

Silitonga, A. S., Ong, H. C., Mahlia, T. M. I., Masjuki, H. H., and Chong, W. T. (2014). "Biodiesel conversion from high FFA crude Jatropha curcas, Calophyllum inophyllum and Ceiba pentandra oil," Enrgy. Proced. 61, 480-483. DOI: 10.1016/j.egypro.2014.11.1153

Strong, A. B. (2008). Fundamentals of Composites Manufacturing, Second Edition: Materials, Methods, and Applications, Society of Manufacturing Engineers, Southfield, MI, USA.

Subbiah, R. (2016). Vacuum Infusion Molding of Natural Fibre Reinforced Biobased Resin Composite, Ph.D. Dissertation, University of Toronto, Toronto, Canada.

Takahashi, T., Hirayama, K., Teramoto, N., and Shibata, M. (2008). "Biocomposites composed of epoxidized soybean oil cured with terpene-based acid anhydride and cellulose fibers," J. Appl. Polym. Sci. 108(3), 1596-1602. DOI: 10.1002/app.27866

Tan, C. L., Azmi, A. I., and Muhammad, N. (2014). "Performance evaluations of carbon/glass hybrid polymer composites," Adv. Mater. Res. 980, 8-12. DOI: 10.4028/www.scientific.net/amr.980.8

Tee, Y. B., Talib, R. A., Abdan, K., Chin, N. L., Kadir Basha, R., and Md Yunos, K. F. 
(2016). "Comparative study of chemical, mechanical, thermal, and barrier properties of poly(lactic acid) plasticized with epoxidized soybean oil and epoxidized palm oil," BioResources 11(1), 1518-1540. DOI: 10.15376/biores.11.1.1518-1540

Tengye, S. (2017). "Plastic heat resistance index and classification," News section, (http://www.sztengye-vacuumforming.com/news/plastic-heat-resistance-index-andclassificati-4452617.html), Accessed 01 Feb 2017.

UL94 (2013). "Standard for tests for flammability of plastic materials for parts in devices and appliances," Underwriters Laboratories, Northbrook, IL, USA.

Vlček, T., and Petrović, Z. S. (2006). "Optimization of the chemoenzymatic epoxidation of soybean oil," J. Am. Oil Chem. Soc. 83(3), 247-252. DOI: 10.1007/s11746-0061200-4

Wang, R. (2014). Manufacturing of Vegetable Oils-Based Epoxy and Composites for Structural Applications, Ph.D. Dissertation, Missouri University of Science and Technology, Rolla, MO, USA.

Wang, X., Li, M., Wu, M., Gu, Y., Li, Y., Wang, S., and Zhang, Z. (2016). "Influence of surface state on moisture sensitivity of carbon fiber and its composite interfacial properties," J. Wuhan Univ. Technol. Mater. Sci. Ed. 31(4), 757-764. DOI: 10.1007/s11595-016-1442-4

Wong, I. M. M., Tan, C. L., Azmi, A. I., Leong, K. W., and Mohd Radzi, M. N. (2014). "Evaluations of mechanical properties and residual strength of drilled glass fiber reinforced polymer (GFRP) composites," Appl. Mech. Mater. 660, 270-274. DOI: 10.4028/www.scientific.net/amm.660.270

Yee, K. F., Lee, K. T., Ceccato, R., and Abdullah, A. Z. (2011). "Production of biodiesel from Jatropha curcas L. oil catalyzed by $\mathrm{SO} 42-/ \mathrm{ZrO}_{2}$ catalyst: Effect of interaction between process variables," Bioresource Technology 102(5), 4285-4289. DOI: 10.1016/j.biortech.2010.12.048

Yusoff, R. B., Takagi, H., and Nakagaito, A. N. (2016). "Tensile and flexural properties of polylactic acid-based hybrid green composites reinforced by kenaf, bamboo and coir fibers," Ind. Crop. Prod. 94, 562-573. DOI: 10.1016/j.indcrop.2016.09.017

Zafar, A., Bertocco, F., Schjødt-Thomsen, J., and Rauhe, J. C. (2012). "Investigation of the long term effects of moisture on carbon fibre and epoxy matrix composites," Compos. Sci. Technol. 72(6), 656-666. DOI: 10.1016/j.compscitech.2012.01.010

Article submitted: December 2, 2019; Peer review completed: February 29, 2020; Revised version received and accepted: April 26, 2020; Published: April 29, 2020. DOI: 10.15376/biores.15.2.4464-4501 